\title{
Impact of the 1991 NHS reforms on the availability and use of coronary revascularisation in the UK (1987-1995)
}

\author{
Nick Black, Susan Langham, Catherine Coshall, John Parker
}

\begin{abstract}
Objective-To describe changes in the availability, utilisation, and waiting times for coronary artery bypass grafting (CABG) and percutaneous transluminal coronary angioplasty (PTCA) between 1987/88 and 1994/95 and to review commissioning of these services. Design-A series of cross sectional surveys and interviews with purchasers and providers. Setting-Four health regions in the United Kingdom. Patients-All residents aged 25 years or more who underwent coronary revascularisation. Results-There has been little change in the availability of consultants in cardiology in specialist centres, while the number of non-consultant cardiologists has risen significantly. The availability of consultant surgeons more than doubled in some regions, while non-consultant surgical staff increased by $40-90 \%$. The NHS rate of use of both CABG and PTCA has increased steadily since 1987/88. In 1994/95, only two districts had CABG rates of less than 300 per million population. The additional contribution of privately funded cases varied between 14-23\% for CABG and 7-30\% for PTCA. Regional rates varied 1.3-fold for CABG and threefold for PTCA in 1994/95, while district rates of CABG varied 3.6-fold and PTCA 18fold. Revascularisation rates were higher in districts with least need in 1991/92 and this persisted over the following three years. The overall waiting time for CABG (214 days) was largely unchanged from $1992 / 93$ (234 days). The overall waiting time for PTCA (138 days) was $25 \%$ shorter than in $1992 / 93$ (185 days). Prioritisation of patients waiting over a year had not yet adversely affected the waiting time of more urgent patients. Commissioning has faced a complex web of interconnected problems which, in general, caused more problems for purchasers than providers initially but which appear to be of increasing concern to providers. Conclusions-The 1991 NHS reforms had had no observable impact on the availability and use of coronary revascularisation by 1995. Continued monitoring is necessary to detect any delayed effect.

Keywords: coronary revascularisation, trends, geographical variation, commissioning
\end{abstract}

Realth Services

Department of Public

Health and Policy,

London School of

Hygiene and Tropical

Medicine, London

N A Black

S Langham

C Coshall

Department of

Cardiac Surgery,

St George's Hospital,

London

D J Parker

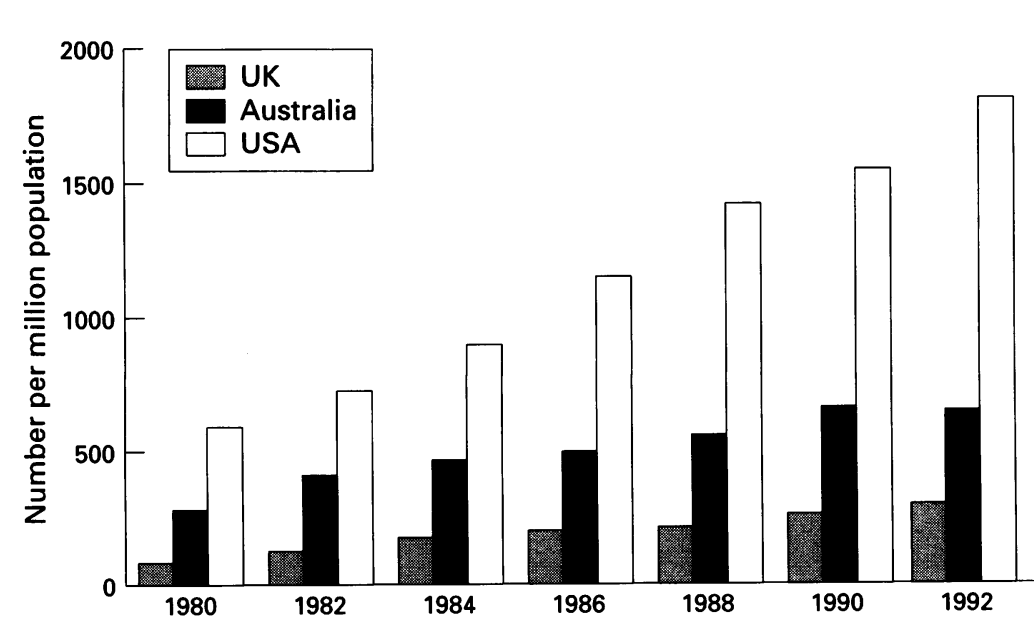

Figure 1 Rate of coronary bypass graft operations per million (without concomitant procedures) in the UK, Australia, and the USA, 1982-1992.

\section{Introduction}

HISTORY OF CORONARY REVASCULARISATION

IN THE UK

Coronary artery bypass grafting (CABG) was

developed in the USA in the late 1960s but was not introduced in the United Kingdom until the early 1970s. By 1982 the rate of surgery (CABG without other procedures) in the UK was 107 per million population compared with 410 per million in Australia and 770 per million in the USA. ${ }^{1}$ In 1981 the rate of surgery varied 12 -fold between regions of the UK from 21 per million to 263 per million. However, these data take no account of patient flows between regions and can therefore only be taken as a crude guide to interregional differences. A consensus development conference held in London in 1984 concluded that a realistic rate for $C A B G$ in the $U K$ should be 300 per million, ${ }^{2}$ a target that was later adopted by the government to be achieved by $1990 .^{3}$

Since the early 1980s the rate of coronary artery surgery has risen steadily to 212 per million in 1986 and 341 per million in 1993/94.4 While the extent of inter-regional differences has fallen from fivefold in 1986 (70 to 381 per million) it was still threefold in 1993/94 (161 to 506 per million). ${ }^{5}$ The CABG rate in the 


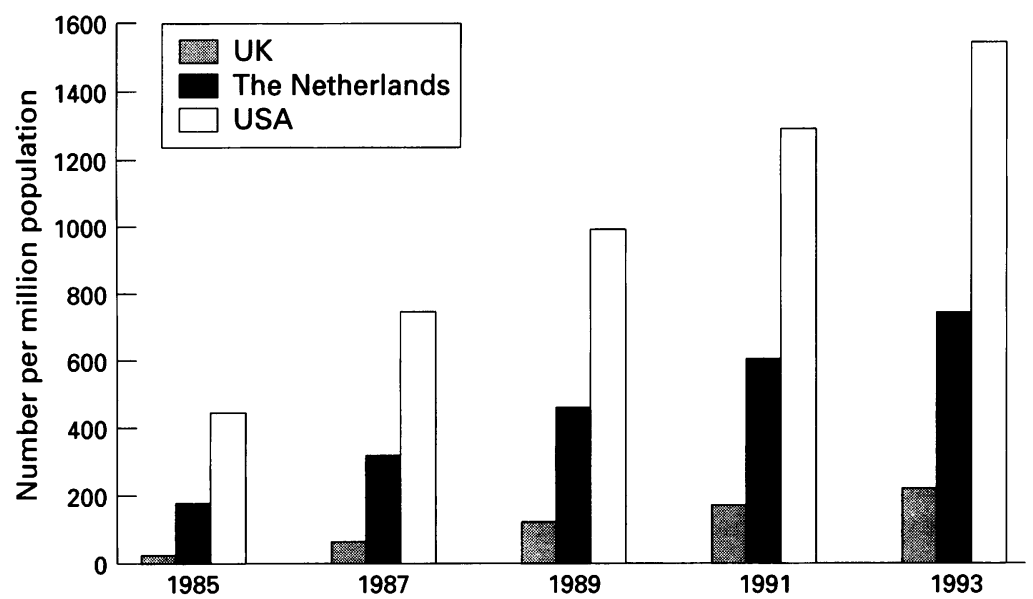

Figure 2 Rate of percutaneous transluminal coronary angioplasty per million in the UK, The Netherlands, and the USA, 1985-1993.

UK has continued to lag behind that in most other industrialised countries (fig 1). In 1992 the rate in Australia was twice that in the UK and the USA rate about four times that in the UK. ${ }^{6}$ By 1994 , the UK rate (for NHS cases, with or without a concomitant procedure) was 403 per million compared with Spain 170, Italy 276, France 349 , Austria 458, Germany 584, and Finland $850 .^{7}$

The number of consultant cardiothoracic surgeons in England and Wales has increased slowly but steadily from 110 in 1979 to 144 in $1994-$ a $31 \%$ rise. Over the same period the overall number of consultants (in all specialties) rose by $40 \%$.

Percutaneous transluminal coronary angioplasty (PTCA) was first performed in 1977 and became widely established in the UK during the early 1980s. By 1985, 15 hospitals performed about 1600 angioplasties, a rate of 29 per million population. ${ }^{8}$ Meanwhile in the USA the rate was 452 per million. The use of the procedure spread rapidly in the UK during the late 1980s so that by 1993 it had reached 230 per million ${ }^{9} 10$ and Hubner PJB, personal communication). Although the rate had risen it still lagged far behind The Netherlands (750 per million) and the USA ( 1553 per million in 1993) (fig 2). In 1991 a report from the Royal Colleges of Physicians (London) and Surgeons (England) has recommended the provision of 300 per million. ${ }^{11}$

The increase in the number of PTCAs in the UK reflects a $62 \%$ increase in the number of consultant cardiovascular physicians in England and Wales, from 223 in 1980 through 270 in 1986 and 323 in 1990 , to 354 in $1993 . .^{12}$ By 1993 there were 6.88 cardiovascular physicians per million population in England and Wales.

\section{AIMS AND OBJECTIVES}

The aims of this study were to describe: the availability and use of CABG and PTCA; the geographical variation that exists within the UK; and the impact of the NHS reforms introduced in April 1991. To achieve these aims, we set ourselves five objectives:

(1) To describe changes in the availability of CABG and PTCA in a representative sample of regions in terms of location, staff, and facilities between 1987/88 and 1994/95.

(2) To compare the age and sex standardised population rates for CABG and PTCA between regions, districts, and boards included in the sample and consider how any differences have changed between 1987/88 and 1994/95 .

(3) To describe the waiting time (a) from general practitioner (GP) referral to outpatients, (b) from outpatients to angiography, and (c) from angiography to CABG or PTCA
Figure 3 NHS and private provider units for residents of South East Thames Region.

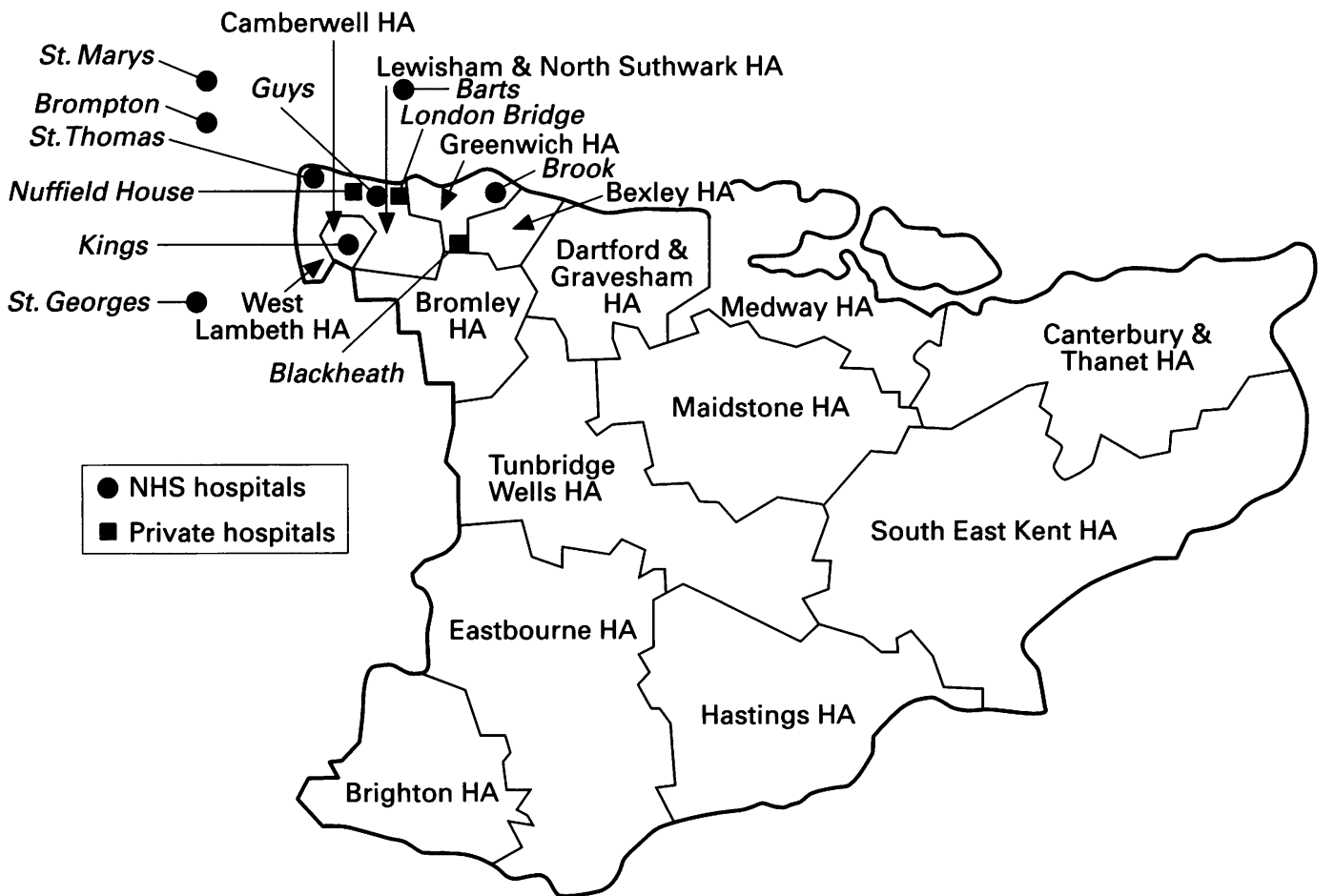




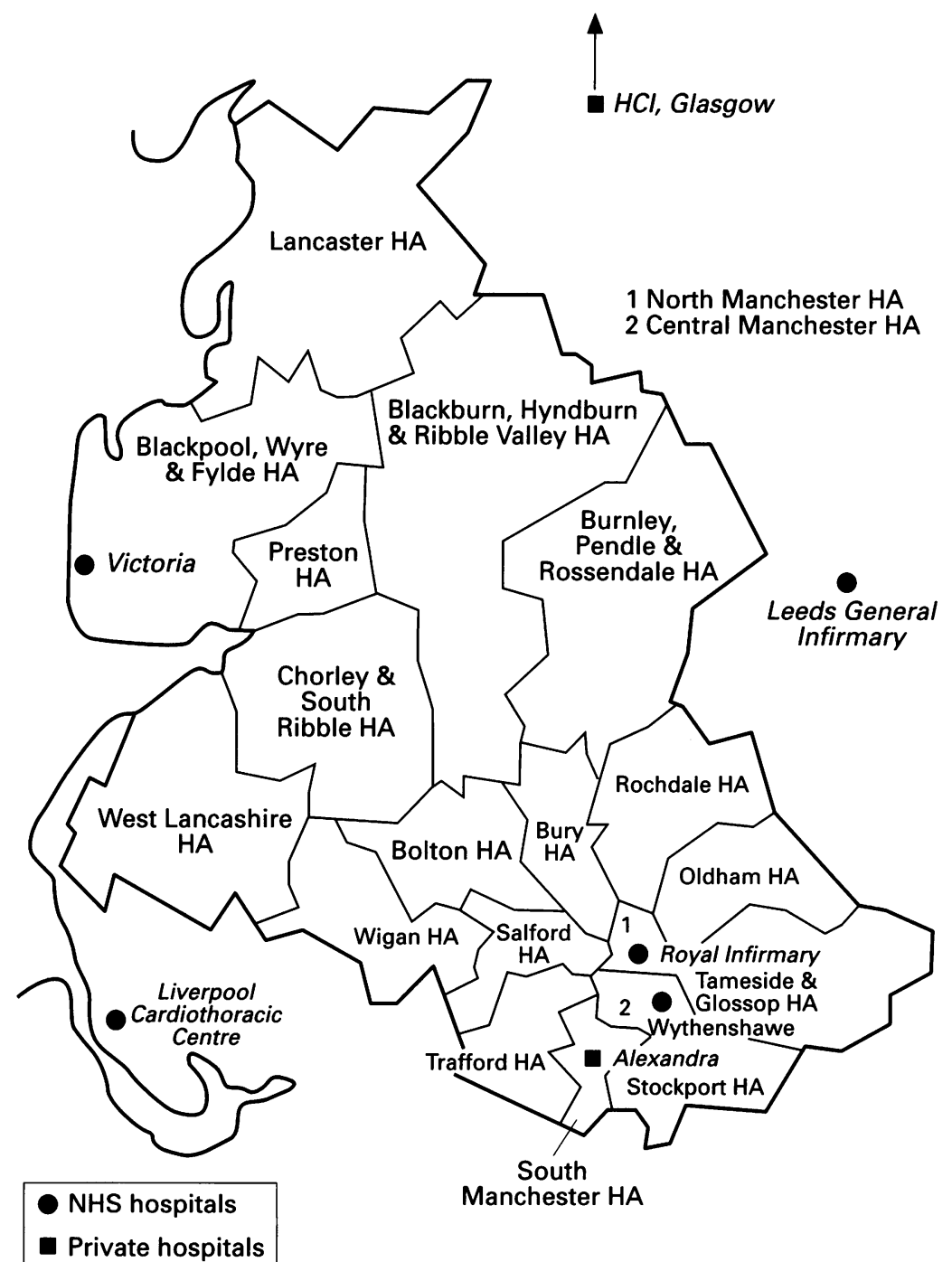

Figure 4 NHS and private provider units for residents of North Western Region.

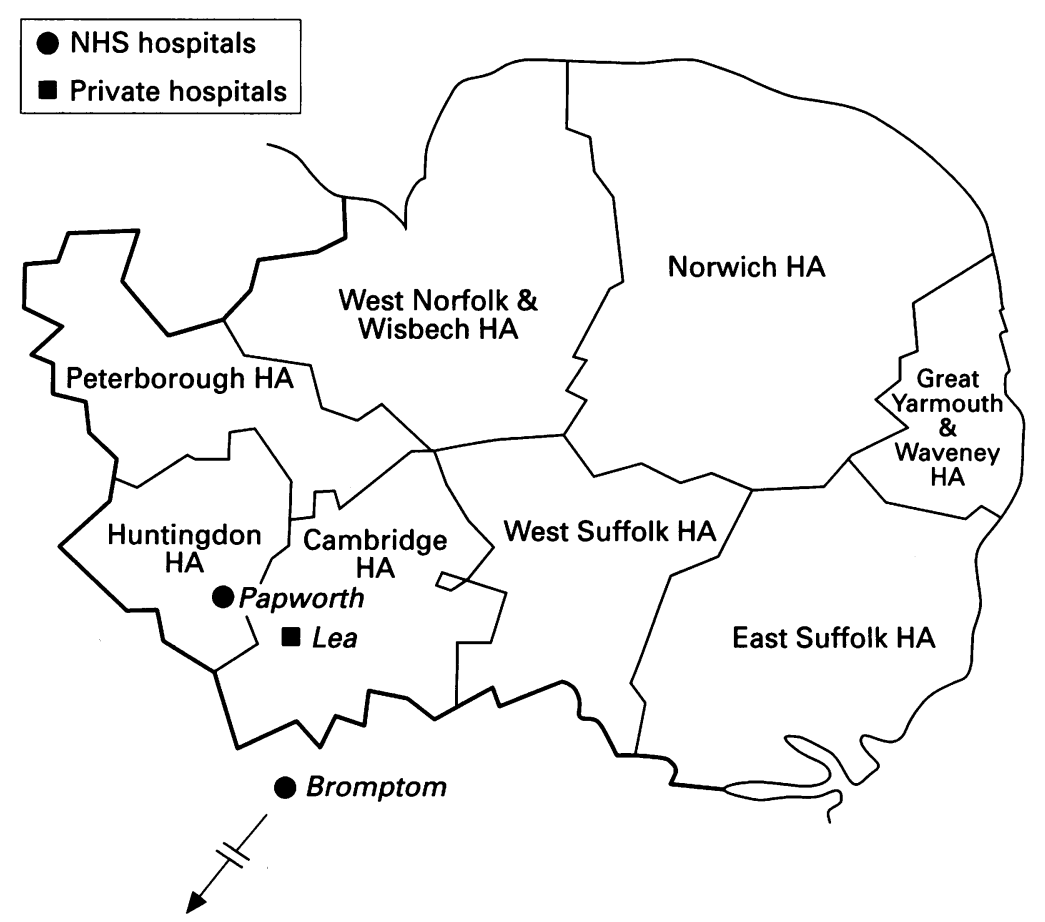

Figure 5 NHS and private provider units for residents of East Anglian Region. in $1992 / 93$ and $1994 / 95$ and how it varied between NHS provider units within the four regions.

(4) To review past, current, and future policies for funding and providing $C A B G$ and PTCA including the types of purchasing contracts being used.

(5) To determine the optimum method for future monitoring arrangements including the completeness of routine NHS data.

\section{Methods}

STUDY SETTING

The study was carried out in three English regions and three Scottish health boards. These were selected to ensure representation of historical levels of provision, population density, geographical location, and initial types of purchasing contracts. The English regions were: (1) South East Thames regionhistorically relatively well funded (fig 3); (2) North Western region-historically underresourced (fig 4); and (3) East Anglian region-with stable funding (fig 5). The Scottish regions were: the Greater Glasgow "region"-an urban Scottish board, plus Lanarkshire and Ayrshire/Arran-two adjacent rural boards (fig 6). This provided a sample of 42 English health districts plus three Scottish boards and covered a total population of 11.6 million ( $20 \%$ of the UK population). For the purposes of this study, the group of three Scottish health boards are referred to as a region. To enable meaningful comparisons over time, the study was based on the 1991 districts, regions and boards despite subsequent mergers and changes.

Data for two periods before the NHS reforms were necessary for a study of time trends. Accurate data before 1987/88 would have been extremely difficult to obtain. We therefore collected data for the financial years $1987 / 88,1989 / 90,1991 / 92,1992 / 93,1993 /$ 94 , and $1994 / 95$.

\section{IDENTIFICATION OF RELEVANT PROVIDERS}

Four categories of providers needed to be identified: intraregional NHS providers; extraregional NHS providers; intraregional private providers; and extraregional private providers.

Intraregional NHS providers were identified by the relevant regional authorities. Interestingly, such authorities were not always certain as to whether or not a provider in their region was undertaking PTCA. The final list of intraregional providers was:
South East Thames: Guy's Hospital
Brook Hospital
St Thomas' Hospital
King's College Hospital
East Anglian:
Papworth Hospital
North Western: Wythenshawe Hospital
Manchester Royal Infirmary
Victoria Hospital, Blackpool 


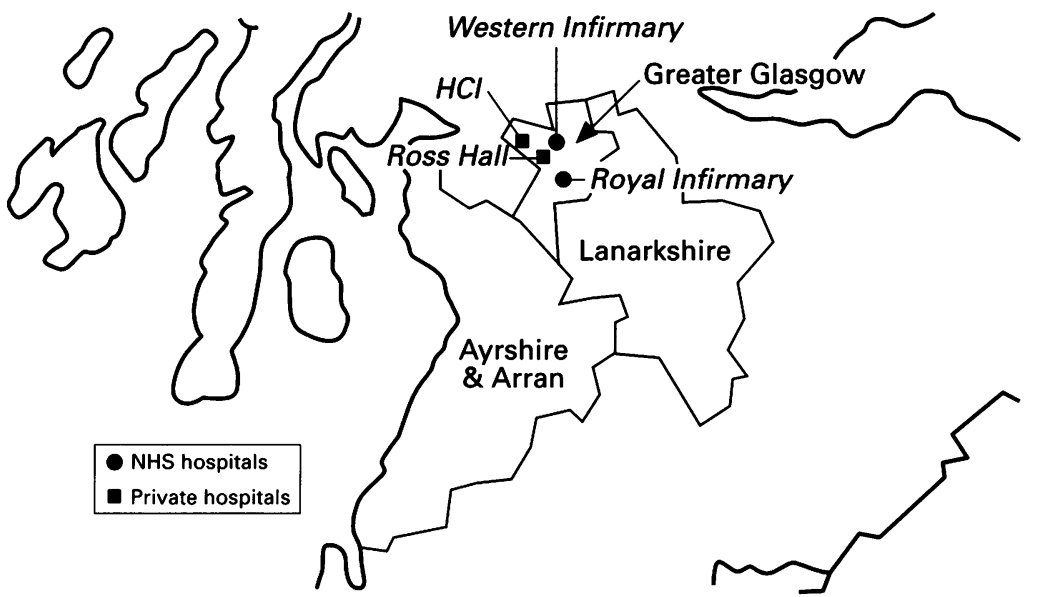

Figure 6 NHS and private provider units for residents of Greater Glasgow "region".

$\begin{array}{cc}\text { Greater Glasgow: } & \begin{array}{c}\text { Glasgow Western } \\ \text { Infirmary } \\ \text { Glasgow Royal } \\ \text { Infirmary }\end{array}\end{array}$

In addition, Ross Hall Hospital and Health

Table 1 Number of residents of the four study regions treated by extraregional NHS providers (1994/95)

\begin{tabular}{|c|c|c|c|c|}
\hline Provider units & SE Thames & E Anglian & $N$ Western & G Glasgow \\
\hline $\begin{array}{l}\text { Cardiothoracic Centre } \\
\text { Liverpool (M) } \\
\text { Freeman (N) } \\
\text { London Chest (NET) } \\
\text { Royal Free (NET) } \\
\text { Middlesex (NET) } \\
\text { St Bartholomew's (NET) } \\
\text { Royal London (NET) } \\
\text { St Mary's (NWT) } \\
\text { Harefield (NWT) } \\
\text { Hammersmith (NWT) } \\
\text { Royal Brompton (NWT) } \\
\text { John Radcliffe (O) } \\
\text { St George's (SWT) } \\
\text { Leicester Groby Road (T) } \\
\text { Northern General (T) } \\
\text { Leeds General Infirmary (Y) } \\
\text { Killingbeck (Y) } \\
\text { Edinburgh Royal Infirmary (L) } \\
\text { Edinburgh Western General (L) }\end{array}$ & 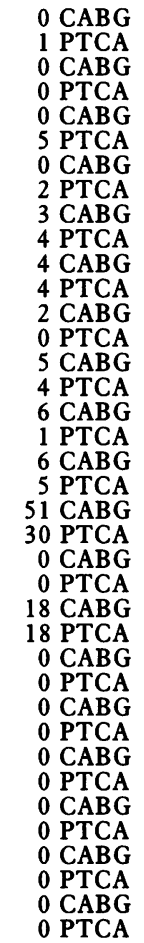 & $\begin{array}{l}0 \text { CABG } \\
0 \text { PTCA } \\
0 \text { CABG } \\
0 \text { PTCA } \\
4 \text { CABG } \\
0 \text { PTCA } \\
0 \text { CABG } \\
0 \text { PTCA } \\
5 \text { CABG } \\
3 \text { PTCA } \\
2 \text { CABG } \\
0 \text { PTCA } \\
3 \text { CABG } \\
0 \text { PTCA } \\
0 \text { CABG } \\
0 \text { PTCA } \\
2 \text { CABG } \\
1 \text { PTCA } \\
1 \text { CABG } \\
1 \text { PTCA } \\
5 \text { CABG } \\
1 \text { PTCA } \\
4 \text { CABG } \\
2 \text { PTCA } \\
1 \text { CABG } \\
0 \text { PTCA } \\
0 \text { CABG } \\
0 \text { PTCA } \\
0 \text { CABG } \\
0 \text { PTCA } \\
0 \text { CABG } \\
0 \text { PTCA } \\
0 \text { CABG } \\
0 \text { PTCA } \\
0 \text { CABG } \\
0 \text { PTCA } \\
0 \text { CABG } \\
0 \text { PTCA }\end{array}$ & $\begin{array}{l}26 \text { CABG } \\
15 \text { PTCA } \\
1 \text { CABG } \\
0 \text { PTCA } \\
0 \text { CABG } \\
0 \text { PTCA } \\
0 \text { CABG } \\
0 \text { PTCA } \\
1 \text { CABG } \\
1 \text { PTCA } \\
0 \text { CABG } \\
0 \text { PTCA } \\
1 \text { CABG } \\
0 \text { PTCA } \\
0 \text { CABG } \\
0 \text { PTCA } \\
1 \text { CABG } \\
2 \text { PTCA } \\
0 \text { CABG } \\
0 \text { PTCA } \\
0 \text { CABG } \\
1 \text { PTCA } \\
0 \text { CABG } \\
0 \text { PTCA } \\
1 \text { CABG } \\
0 \text { PTCA } \\
0 \text { CABG } \\
0 \text { PTCA } \\
1 \text { CABG } \\
4 \text { PTCA } \\
14 \text { CABG } \\
1 \text { PTCA } \\
0 \text { CABG } \\
0 \text { PTCA } \\
0 \text { CABG } \\
0 \text { PTCA } \\
0 \text { CABG } \\
0 \text { PTCA }\end{array}$ & $\begin{array}{l}0 \text { CABG } \\
0 \text { PTCA } \\
0 \text { CABG } \\
0 \text { PTCA } \\
0 \text { CABG } \\
0 \text { PTCA } \\
0 \text { CABG } \\
0 \text { PTCA } \\
1 \text { CABG } \\
0 \text { PTCA } \\
0 \text { CABG } \\
0 \text { PTCA } \\
0 \text { CABG } \\
0 \text { PTCA } \\
0 \text { CABG } \\
0 \text { PTCA } \\
0 \text { CABG } \\
0 \text { PTCA } \\
0 \text { CABG } \\
0 \text { PTCA } \\
0 \text { CABG } \\
0 \text { PTCA } \\
0 \text { CABG } \\
0 \text { PTCA } \\
0 \text { CABG } \\
0 \text { PTCA } \\
0 \text { CABG } \\
0 \text { PTCA } \\
0 \text { CABG } \\
0 \text { PTCA } \\
0 \text { CABG } \\
0 \text { PTCA } \\
0 \text { CABG } \\
0 \text { PTCA } \\
0 \text { CABG } \\
0 \text { PTCA } \\
0 \text { CABG } \\
0 \text { PTCA }\end{array}$ \\
\hline Total & $\begin{array}{r}105 \text { CABG } \\
74 \text { PTCA }\end{array}$ & $\begin{array}{r}27 \text { CABG } \\
8 \text { PTCA }\end{array}$ & $\begin{array}{l}46 \text { CABG } \\
24 \text { PTCA }\end{array}$ & $\begin{array}{l}1 \text { CABG } \\
0 \text { PTCA }\end{array}$ \\
\hline
\end{tabular}

Table 2 Number of residents of the four study regions treated privately by intraregional private providers (1994/94)

\begin{tabular}{lrrrr}
\hline Providers in: & SE Thames & E Anglian & \multicolumn{1}{c}{$N$ Western } & \multicolumn{1}{c}{ G Glasgow } \\
\hline SE Thames & 396 CABG & 1 CABG & 0 CABG & 1 CABG \\
& 70 PTCA & 0 PTCA & 0 PTCA & 0 PTCA \\
E Anglian & 0 CABG & 50 CABG & 0 CABG & 0 CABG \\
& 0 PTCA & 26 PTCA & 0 PTCA & 0 PTCA \\
NWestern & 0 CABG & 0 CABG & 248 CABG & 0 CABG \\
& 0 PTCA & 0 PTCA & 19 PTCA & 0 PTCA \\
G Glasgow & 0 CABG & 0 CABG & 38 CABG & 144 CABG \\
& 0 PTCA & 0 PTCA & 2 PTCA & 27 PTCA \\
Total & 396 CABG & 51 CABG & 286 CABG & 145 CABG \\
& 70 PTCA & 26 PTCA & 21 PTCA & 27 PTCA \\
\hline
\end{tabular}

Care International's Hospital (private hospitals) in Glasgow have provided services for NHS funded patients.

Identification of extraregional NHS providers proved more difficult as no one in the study regions was certain where residents were treated outside their region. As a result, data were requested from all providers who it was felt might have treated residents of the study regions during 1991/92 and during 1994/95. It was assumed that the numbers treated in earlier years would have been lower. In view of the very small numbers of patients some of these provider units treated (table 1 shows data for 1994/95) it was decided that to collect data on every patient treated outside their own region would not be cost-effective. Instead, the aim was to ensure at least $97 \%$ of resident cases (intraregional plus extraregional) were included. The minimum number of hospitals that were needed to achieve this was six:

South East Thames: Royal Brompton National Heart and Lung Hospital St Mary's

St Bartholomew's

St George's

East Anglian: $\quad$ Royal Brompton National Heart and Lung Hospital

North Western: $\quad$ Cardiothoracic Centre, Liverpool

Leeds General Infirmary

Discussions with purchasers and NHS providers in the study regions revealed that no NHS patients were treated by private providers apart from Greater Glasgow, which paid for some to be treated in Ross Hall Hospital, and North Western region, which paid for some to be treated in Health Care International's hospital in Glasgow. With these exceptions, private providers were not directly relevant to the aim of this study. However, in view of the increasing role of private providers in the field of elective procedures, it was felt to be important to collect data on their contribution so as to obtain a more complete picture.

Intraregional private providers were easily identified by local clinicians and managers:

\section{South East Thames: Blackheath}

London Bridge

Nuffield House, Guy's

East Anglian:

North Western: Greater Glasgow:

Lea, Cambridge

Alexandra

Ross Hall

Health Care International

The numbers of procedures performed in these hospitals on the residents of the four study regions are shown in table 2 .

Identification of relevant extraregional private providers required a similar exercise to that for extraregional NHS providers. A list of potential private providers was obtained from the Independent Hospitals Federation. Initially, the Association wrote to all their 
Table 3 Number of residents of the four study regions treated privately by extraregional private providers (1994/95)

\begin{tabular}{lcccc}
\hline Providers in: & SE Thames & E Anglian & $N$ Western & G Glasgow \\
\hline NE Thames & 19 CABG & 1 CABG & 0 CABG & 0 CABG \\
& 28 PTCA & 4 PTCA & 0 PTCA & 0 PTCA \\
NW Thames & 45 CABG & 1 CABG & 9 CABG & 0 CABG \\
& 11 PTCA & 0 PTCA & 0 PTCA & 0 PTCA \\
SW Thames & 11 CABG & 0 CABG & 0 CABG & 0 CABG \\
& 6 PTCA & 0 PTCA & 0 PTCA & 0 PTCA \\
Trent & 0 CABG & 3 CABG & 0 CABG & 0 CABG \\
& 0 PTCA & 3 PTCA & 0 PTCA & 0 PTCA \\
Yorkshire & 0 CABG & 1 CABG & 1 CABG & 0 CABG \\
& 0 PTCA & 0 PTCA & 0 PTCA & 0 PTCA \\
Total & 75 CABG & 6 CABG & 10 CABG & 0 CABG \\
& 45 PTCA & 7 PTCA & 0 PTCA & 0 PTCA \\
\hline
\end{tabular}

Table 4 Number (\%) of CABGs performed on residents of our study regions in 1994/95 by different categories of providers, and proportion of cases including in study

\begin{tabular}{|c|c|c|c|c|}
\hline & \multicolumn{4}{|l|}{ Study regions } \\
\hline & SE Thames & E Anglian & $N$ Western & G Glasgow \\
\hline $\begin{array}{l}\text { NHS purchaser } \\
\text { - Intraregional NHS providers } \\
\text { - Extraregional NHS providers } \\
\text { - Private providers } \\
\text { Subtotal }\end{array}$ & $\begin{array}{c}1464(73) \\
74(4) \\
0(0) \\
1538(77)\end{array}$ & $\begin{aligned} & 828(84) \\
& 8(1) \\
& 0(0) \\
& 836(85)\end{aligned}$ & $\begin{array}{r}1221(81) \\
39(2) \\
1(0) \\
1461(83)\end{array}$ & $\begin{array}{c}896(84) \\
0(0) \\
30(2) \\
926(86)\end{array}$ \\
\hline $\begin{array}{l}\text { Private purchaser } \\
\text { - Intraregional private provider } \\
\text { - Extraregional private provider } \\
\text { - Intraregional NHS provider } \\
\text { Subtotal }\end{array}$ & $\begin{aligned} & 396(19) \\
& 75(4) \\
& 7(0) \\
& 468(23)\end{aligned}$ & $\begin{array}{c}51(5) \\
6(1) \\
89(9) \\
146(15)\end{array}$ & $\begin{array}{l}248(14) \\
10(1) \\
42(2) \\
300(17)\end{array}$ & $\begin{aligned} & 145(14) \\
& 1(0) \\
& 0(0) \\
& 146(14)\end{aligned}$ \\
\hline $\begin{array}{l}\text { Total } \\
\text { Total included in study }(\%)\end{array}$ & $\begin{array}{l}2006 \\
1521^{\star}(99)\end{array}$ & $\begin{array}{l}982(100) \\
963(98)\end{array}$ & $\begin{array}{l}1761(100) \\
1756(100)\end{array}$ & $\begin{array}{l}1072(100) \\
1071(100)\end{array}$ \\
\hline
\end{tabular}

* Only NHS purchased cases were included for SE Thames in the study due to lack of availability of data from some private providers.

Table 5 Number (\%) of PTCAs performed on residents of our study regions in 1994/95 by different categories of providers, and proportion of cases including in study

\begin{tabular}{|c|c|c|c|c|}
\hline & \multicolumn{4}{|l|}{ Study regions } \\
\hline & SE Thames & E Anglian & $N$ Western & G Glasgow \\
\hline $\begin{array}{l}\text { NHS purchaser } \\
\text { - Intraregional NHS providers } \\
\text { - Extraregional NHS providers } \\
\text { - Private providers } \\
\text { Subtotal }\end{array}$ & $\begin{array}{c}1304(88) \\
51(4) \\
0(0) \\
1355(99)\end{array}$ & $\begin{array}{c}380(79) \\
0(0) \\
0(0) \\
380(79)\end{array}$ & $\begin{array}{c}445(90) \\
13(3) \\
0(0) \\
458(93)\end{array}$ & $\begin{array}{c}332(92) \\
0(0) \\
0(0) \\
332(92)\end{array}$ \\
\hline $\begin{array}{l}\text { Private purchaser } \\
\text { - Intraregional private provider } \\
\text { - Extraregional private provider } \\
\text { - Intraregional NHS provider } \\
\text { Subtotal }\end{array}$ & $\begin{array}{r}70(5) \\
45(3) \\
12(0) \\
127(8)\end{array}$ & $\begin{array}{r}18(4) \\
3(0) \\
80(17) \\
101(21)\end{array}$ & $\begin{array}{r}19(4) \\
0(0) \\
18(3) \\
37(7)\end{array}$ & $\begin{array}{r}27(8) \\
0(0) \\
0(0) \\
27(8)\end{array}$ \\
\hline $\begin{array}{l}\text { Total } \\
\text { Total included in study }(\%)\end{array}$ & $\begin{array}{l}1482 \\
1355^{\star}(100)\end{array}$ & $\begin{array}{l}481(100) \\
474(99)\end{array}$ & $\begin{array}{l}495(100) \\
488(99)\end{array}$ & $\begin{array}{l}359(100) \\
359(100)\end{array}$ \\
\hline
\end{tabular}

^Only NHS purchased cases were included for SE Thames in the study due to lack of availability of detailed data from some private providers.

members to ascertain whether or not they undertook CABG or PTCA. As only a few responded we approached the others directly by telephone. We then wrote to the 13 hospitals which carried out CABG or PTCA and were located near the four study regions to find out the numbers of patients they had treated in $1991 / 92$ and in 1994/95 from those regions (table 3). Data on individual patients were then requested from the four hospitals which provided services for residents of the four study regions. Despite repeated requests, several hospitals in London were unable or unwilling to provide such data. It was therefore not possible to include private provision in the detailed analyses of South East Thames region. In addition it had to be assumed that few if any residents of the three other study regions were treated privately in the four hospitals which did not provide data.

The relative contributions of the different categories of providers of CABG can be seen in table 4. Most operations were paid for by the NHS $(86 \%$ in Greater Glasgow, $85 \%$ in East Anglian, $83 \%$ in North Western, and $77 \%$ South East Thames). Apart from 30 patients in Greater Glasgow (and one in North Western), these patients were treated exclusively in NHS hospitals. Inter-regional flow of NHS purchased care was slight. The same was true for privately funded cases in that most were treated in local private or NHS hospitals.

As with CABG, most PTCAs were funded by the NHS $(93 \%$ in North Western, $92 \%$ in Greater Glasgow and South East Thames, and $78 \%$ in East Anglian) (table 5). Almost all were carried out in NHS hospitals within the region. The pattern of provision of private cases differed between regions. In East Anglian most were performed in an NHS hospital, whereas in Greater Glasgow all were carried out in private hospitals. There was less cross boundary flow than was seen with CABG.

DATA

Sources

Initially several national sources of data were investigated but none of them proved to be of value to this study:

British Cardiac Society-Collected data on the annual number of PTCAs performed in each provider unit between 1985 and 1989 . However, no sociodemographic details of the patients were collected.

British Cardiovascular Intervention SocietyHas collected data on the annual number of PTCAs performed in each provider unit since 1988. No sociodemographic details of patients are collected.

Society of Cardiothoracic Surgeons-Has collected data on surgical activity from all NHS surgical units every year since 1977 . These data do not identify the residence of the patients.

Private health insurance associations (BUPA, PPP, WPA) were unable to identify the residence of many of the patients of their corporate subscribers.

College of Health could provide information on waiting times for each NHS provider but only at the specialty level and not for individual procedures.

Hospital In-patient Episode (HIPE) was based on a $10 \%$ sample of admissions but it ended in 1985 and would not have been sensitive enough for determining district rates.

Hospital Episode System (HES) is available from each region but there are serious doubts about its completeness and accuracy.

\section{Availability of services}

Information on the NHS services available in regional centres within each of the study regions was obtained from a variety of regional and provider unit sources. The data about regional centres that were required for five of the years being studied were: number of whole time equivalent (WTE) medical staff by grade 
in cardiac surgery and in cardiology; and number of available beds in cardiac surgery, cardiology, ITU/CCU, and high dependency.

The use of medical staffing levels in regional centres as an indicator of the availability of PTCA assumes that the staff in each centre devote similar proportions of their time to this procedure. This may not be true. For example, some cardiologists working in a regional centre may not perform coronary angioplasties. Conversely, some cardiologists in district hospitals spend some sessions in regional centres performing angiograms and, in some circumstances, angioplasties. Due to difficulties in obtaining accurate data on the number of sessions spent by medical staff on PTCA, it was decided to use the number of whole time equivalent staff based in the intraregional centres as an indicator of availability of staff.

Staffing levels and bed numbers in cardiac surgery attempted to exclude services that were devoted to thoracic surgery. To achieve this, the resources devoted to cardiac surgery in some hospitals had to be based on an estimate of the proportion of staff time and beds devoted to cardiac rather than thoracic surgery. Inevitably these estimates were subject to individual interpretation at each centre and this may have introduced some inaccuracies. Another minor error was introduced by choosing to ignore the availability of private facilities being used for NHS funded patients.

Although information was collected on medical and surgical staff by grade, it was decided to consider just two categoriesconsultant and non-consultant. This was partly because of the small numbers of whole time equivalent staff in some specific training grades, and partly because of the variety of terms used to designate non-consultant staff. This category therefore includes: senior registrar; associate specialist; staff grade; lecturer; registrar; research registrar; senior house officer; and house officer. Having obtained the most accurate data available, they were sent to a senior cardiac surgeon and cardiologist in each of the regional centres for checking and, where necessary, correcting.

Data on the number of ITU, CCU, and high dependency beds were collected but not used. This was for several reasons: in some hospitals, cardiac surgery had exclusive use of an ITU whereas in others the ITU was shared with other specialties; one hospital had few CCU beds as they were not the main centre for emergency medical admissions; and definitions of high dependency varied. Data on ward beds included day care beds.

Availability of NHS services within each of the study regions was determined by relating the staffing and bed levels in the regional centres to the resident population. This definition of availability is based on the assumption that it is NHS policy to achieve a regionally equitable distribution of services. The provider units included were therefore the NHS hospitals within the study regions. No account was taken of services provided for NHS patients treated in private hospitals or private facilities provided in NHS hospitals.
Demographic data were required for each of the health districts and boards included in the study. These were obtained from the regional authorities and OPCS. The resident population used to determine the rate of provision of services was men and women aged over 24 years. As few people below this age are treated in adult departments, the calculated rates are a more accurate reflection, for comparative purposes, of the availability of services. For Greater Glasgow region, it was assumed that the NHS provider units in Glasgow served an area which includes not only the three health boards covered in this study but also the Western Isles, Argyll/Clyde, Dumfries/ Galloway, and half of Forth Valley health board.

\section{Use of services}

The study was confined to all patients undergoing either CABG (OPCS codes K40-K46) or PTCA (OPCS codes K49-K50) without any other procedure, such as valvar surgery. Patients undergoing both CABG and PTCA within the same financial year were counted twice. In view of the poor quality of much clinical information in routine health service databases (particularly for the earlier years) it was decided that data would be collected from provider units. This would also enable the accuracy of routine data collection (Hospital Episode System in England; SMR1 system in Scotland) to be assessed. The analyses identified both NHS and privately funded cases treated both in NHS and in private hospitals.

The following data were required on each resident of the study regions who underwent CABG or PTCA during the relevant years: sex, age, procedure, provider unit, health district or board of residence. No attempt was made to collect data on outcome as it was felt to be outside the terms of reference of this study.

Data on the use of CABG and PTCA by residents of the study regions were collected from the 10 intraregional and six extraregional NHS providers and seven intraregional private providers. When the district of residence of patients was not known by the hospital, the district had to be identified from the post code. If neither the health district nor post code were present, the patient's address had to be used. This involved manually identifying each patient's post code from post code registers and adding these to the database. Having ensured all patients had a valid post code, the appropriate health district was identified using a commercial software package. Patients whose age was unknown (about 2\% of the entire database) were distributed across the age range according to the age distribution of the majority of patients whose ages were known.

The raw data were entered using dBASE and then transferred to a spreadsheet using Lotus 123. The data were then analysed using EPI-INFO. District utilisation rates directly standardised for sex and age (25-44, 45-54, $55-64,65-74,75$ or more years) were calculated for each procedure for each year of the 
study for NHS provision and private provision separately. This takes account of differences between districts in the age and sex of their residents. The use of services by residents of the four study regions was considered in three categories: treated as NHS patients within their region; treated as NHS patients outside their region; treated privately either within or outside their region. The rates are expressed as per million residents aged over 24 years. To derive approximate district rates per million total population the district figures need to be multiplied by 0.67 . Note that a rate of 300 per million total population is equivalent to about 450 per million aged over 24 years.

Variation between districts and secular trends are described. Comparisons of the extent of interdistrict variation within each region were made using the systematic component of variation. ${ }^{13}$ This takes into account differences in the mean regional rate and differences in the sizes of the district populations, both of which will influence the amount of random variation. Values below about 4 indicate low variation, 5-10 moderate variation, and above 10, high variation. Examples of other surgical procedures are inguinal herniorrhaphy (low), prostatectomy (moderate), and tonsillectomy (high).

\section{Waiting times}

None of the hospitals was able to provide sufficiently detailed or accurate data on waiting times. The only source capable of providing the dates of all stages of specialist care (first referral to cardiologist; first cardiology appointment; coronary angiogram; first seen by surgeon; surgical operation) was the patient's case notes. Given the difficulties of obtaining and extracting data from case notes it was decided to confine this part of the study to intraregional NHS providers during 1994/95.

Seventy consecutive admissions (elective, emergency, and transfers) for CABG and the same number for PTCA were identified from computer or manual registers. A specially designed form was used by the medical records officer recruited to undertake data

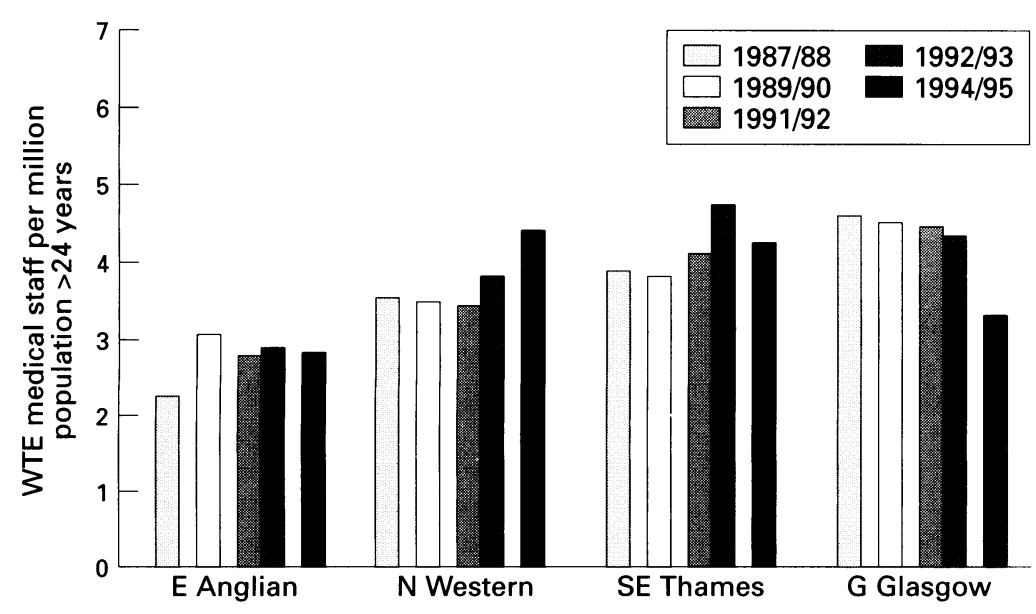

Figure 7 Availability of consultant cardiologists per million population over 24 years of age in the four study regions (1987-1995). extraction. If a patient's case notes were unobtainable the next consecutive admission (after the first 70) was sought and included. The retrieval rate for each hospital is presented with the analyses of waiting times in terms of means, standard deviations, and medians. Some of the longest waiting times do not actually reflect waiting. For example a patient may be under the care of a cardiologist for several years before it is felt appropriate to carry out a coronary angiogram. To avoid such cases distorting the more usual experience of waiting, the data were also analysed having excluded the $10 \%$ of patients who waited the longest time in each waiting period, regardless of hospital. The anonymity of the participating hospitals has been maintained in accordance with their wishes. The statistical significance of differences in mean waiting times were tested for using analysis of variance (ANOVA). Finally, the waiting times in each hospital were compared with data previously collected in a similar way for $1992 / 93$.

\section{Completeness of routine NHS data}

To test the completeness of routine NHS information, Hospital Episode System data were obtained from the four regions for $1991 / 92$, 1992/93, 1993/94, and 1994/95. Comparisons could then be made with the data painstakingly derived from provider units. This was not possible for CABG in Greater Glasgow region as the routine data are supplied by the Scottish Cardiac Surgical Register, the same source as that used in this study.

\section{Commissioning}

A review of the literature on commissioning revealed the key areas of interest and concern. This was used to develop a form for use in semi-structured interviews with purchasers and providers. The form was modified after it had been piloted at three sites. Many of the questions (which concerned 1991/92, $1992 / 93,1993 / 94$ and 1994/95) were the same both for purchasers and providers:

- When did the region start operating on a contractual basis for the services?

- How many contracts have been agreed, with whom and do you intend to increase or decrease this total in the future?

- What type of contracts are currently being used?

- Do you plan to change the nature of contracts in the future?

- Have there been any problems with the contracts?

- What quality standards are specified in contracts?

- Is there specification for an adequate audit system to ensure that the quality standards are adhered to?

- What is the situation concerning extra-contractual referrals?

- What problems have occurred?

In addition, purchasers were asked the following:

- What methods do you use for placing, agreeing and monitoring your contracts? 


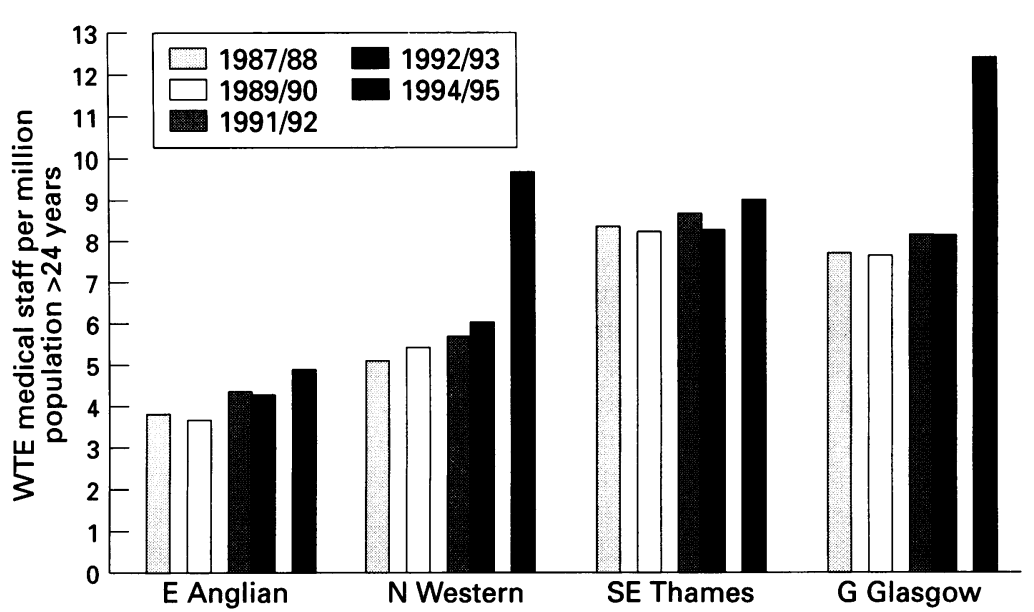

Figure 8 Availability of non-consultant cardiologists per million population over 24 years of age in the four study regions (1987-1995).

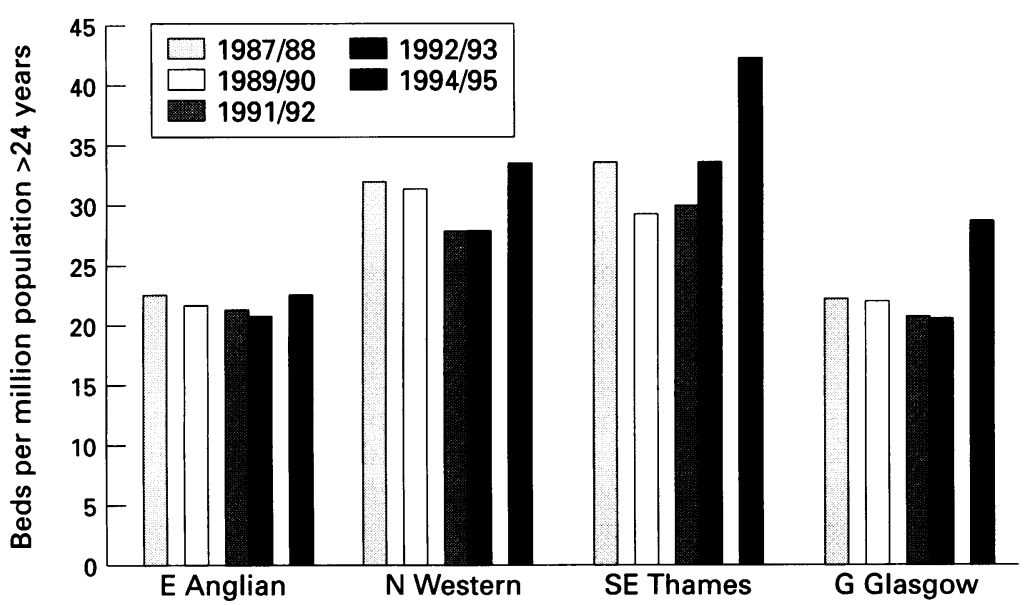

Figure 9 Availability of cardiology beds per million population in the four study regions (1987-1995).

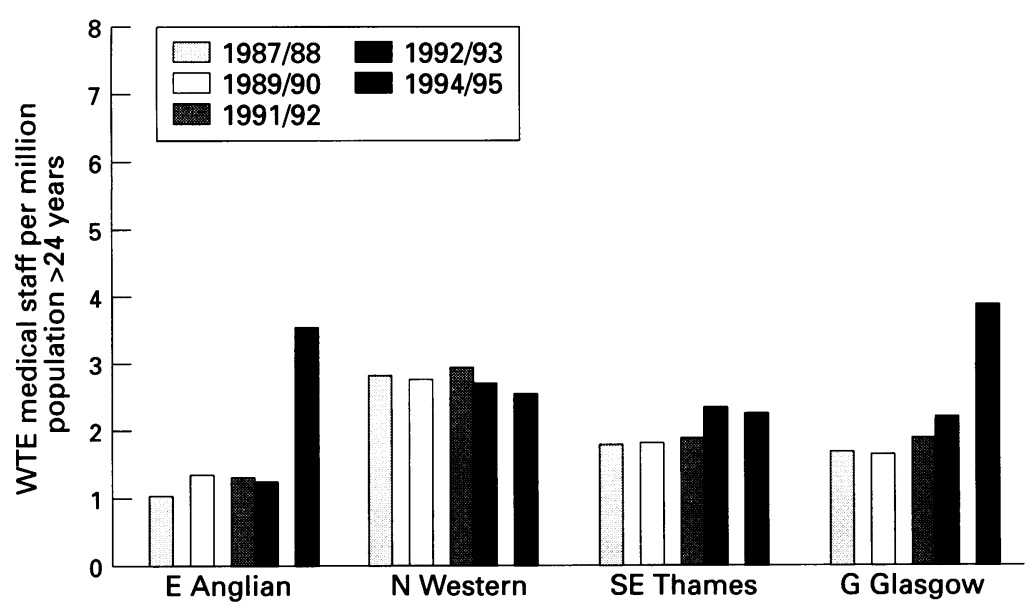

Figure 10 Availability of consultant cardiac surgeons per million population over 24 years of age in the four study regions (1987-1995).

- Who is responsible for drawing up and negotiating the contracts?

- What type of relationship do you have with your main provider?

- What is the proposed future development of the contracting process?

- What type of resource distribution are you adopting and what is the proposed future development in this area?

- Is joint purchasing currently being pursued?
And providers were asked the following additional questions:

- What is your policy for handling clinical priority?

- What methods do you use to price procedures?

- What type of relationship do you have with your main purchaser?

Business managers of all 10 intraregional NHS providers in the four regions were interviewed. Thirteen purchasers were selectedon the advice of providers - as being particularly interested and active in contracting these services. They included regional staff, district staff, and general practitioner fund holders. In Scotland, in addition to the person responsible for purchasing for the Greater Glasgow Health Board, a member of the NHS Management Executive in Edinburgh was interviewed, as were members of the Lanarkshire and Ayr/Arran Health Boards. The interviews lasted about one hour and information was collected either by making notes during and after the interviews or by audiotaping. In addition, other purchasers were written to and invited to comment on their experiences of commissioning.

Results

AVAILABILITY OF SERVICES

There has been little or no change between $1987 / 88$ and $1994 / 95$ in the availability of consultant cardiologists in regional centres (though the proportion of staff trained to perform PTCA has risen) (fig 7). Detailed data appear in Appendix 1. The decrease in Greater Glasgow in 1994/95 resulted from two full time consultants reducing their commitment. In contrast, while the availability of non-consultant doctors in cardiology has risen only slightly in East Anglian and South East Thames it rose substantially in North Western and Greater Glasgow (fig 8). This is in marked contrast to the national policy of shifting to a consultant based service with strict manpower controls on training posts. Some of the observed increase appears to be the result of additional research registrars. The availability of cardiology beds in regional centres has remained the same in East Anglian and North Western but risen recently in South East Thames and Greater Glasgow (fig 9). Part of the explanation for this may be the addition of day case beds for investigations and minor procedures.

Data from the British Cardiac Society show that the number of whole time equivalent consultant cardiologists (including paediatrics) in all four regions increased between 1991/92 and 1994/95: East Anglian rose 26\% (9.5 to 12 ), North Western by $33 \%$ (24 to 32), South East Thames by $12 \%(29$ to $32 \cdot 5)$, and Greater Glasgow by $20 \%$ (23 to $27 \cdot 5)$. By $1994 / 95$ only four of the 45 districts/boards in the study were without a cardiologist. This compares with eight districts in 1991/92.

The rate of provision of services varies between regions. In 1994/95, North Western and South East Thames had about $50 \%$ more 


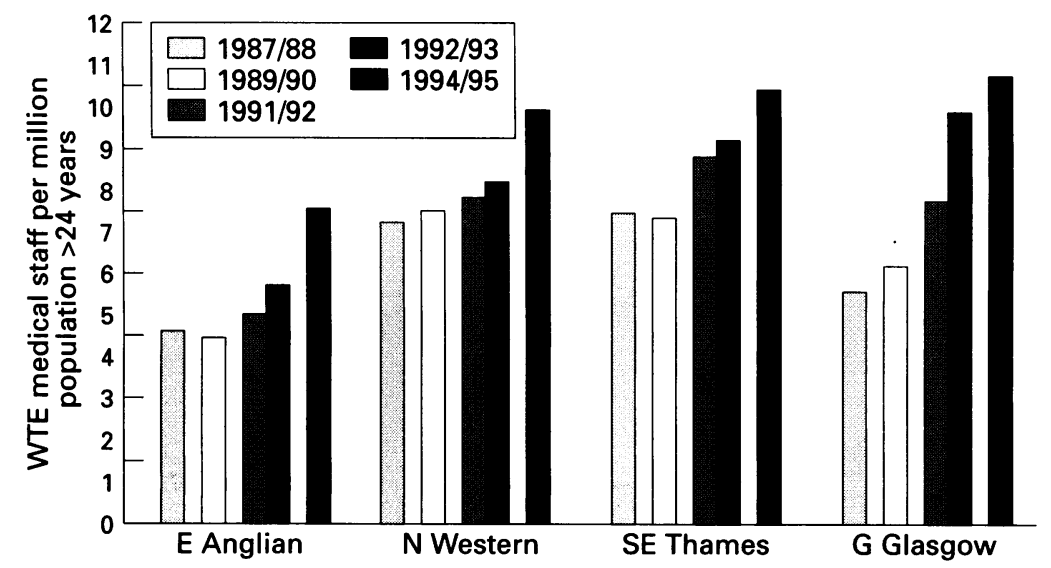

Figure 11 Availability of non-consultant cardiac surgeons per million population over 24 years of age in the four study regions (1987-1995).

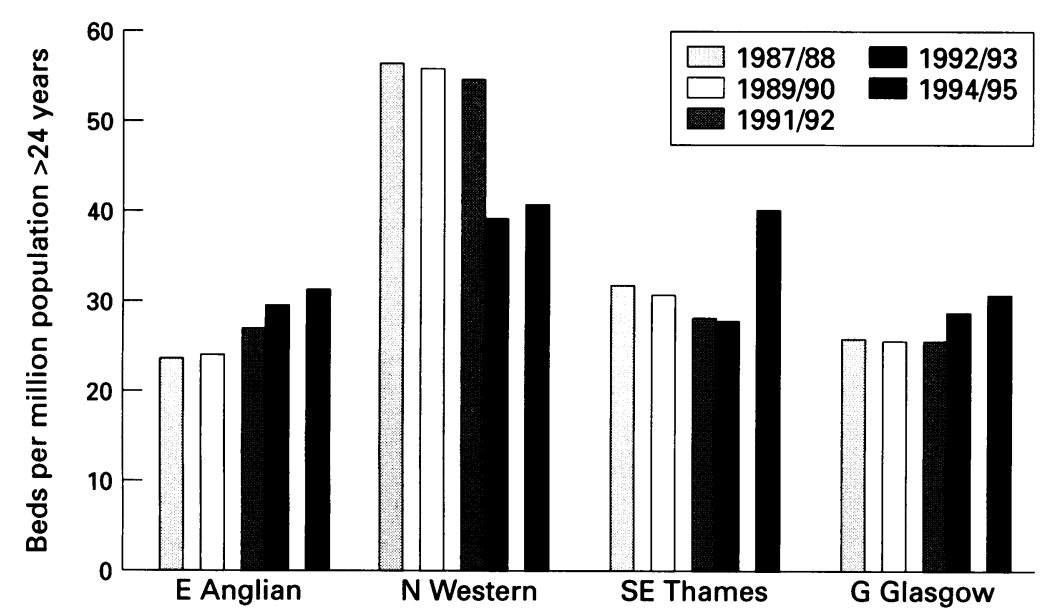

Figure 12 Availability of cardiac surgical beds per million population in the four study regions (1987-1995).
The most striking changes in the provision of cardiac surgical services have been the increase in staffing levels in all four regions. Consultant levels more than doubled in East Anglian and Greater Glasgow, though the increase in South East Thames was only $27 \%$ and there was no increase in North Western (fig 10). As a result, East Anglian has changed from its historically low level to being the best provided of the three English study regions. Increases in non-consultant staffing levels have been more widespread-about $40 \%$ in South East Thames and North Western, 65\% in East Anglian, and 90\% in Greater Glasgow (fig 11). These increases have been most notable in the years after April 1991. As with cardiology, this change does not reflect the national policy of shifting towards a consultant led service. The other change has been in bed provision (fig 12). Whereas East Anglian and Greater Glasgow have experienced modest increases, bed provision fell dramatically in North Western region in 1992/93 from its historically high level. Even more striking has been the recent increase in South East Thames. The reason for this is unclear, though it only served to raise the bed provision per CABG in $1994 / 95$ to a similar level to that in East Anglian and North Western.

Inter-regional differences in surgical staffing levels are as pronounced as for cardiologists. Historically, East Anglian had about half the number of consultants per million population as the other three regions (fig 10), though the difference had disappeared by 1994/95. East Anglian continued, however, to have the lowest provision of non-consultant surgical staff (fig 11). The ratio of consultants to non-consultants was about 1:2 in South East Thames, North Western and Greater Glasgow, whereas in East Anglian it was about 1:1 due to the recent substantial increases in the number of consultants. In contrast, bed provision is much more similar, with two regions having about 30 per million population and the other two having about 40 per million. The number of beds per consultant in 1994/95 varied from 5.0 in Greater Glasgow and 7.7 in East Anglian to 9.6
Figure 13 Age-sex standardised NHS coronary revascularisation rates (per million population) for the four study regions combined (1987/88-1994/95). consultants than East Anglian (fig 7). In addition, East Anglian had about half the number of non-consultants per million population than the other three regions (fig 8). Bed provision also varied-South East Thames had almost twice that of East Anglian (fig 9). However, in 1994/95 the number of beds per consultant varied little-from 7.5 in North Western to 10.1 in South East Thames.

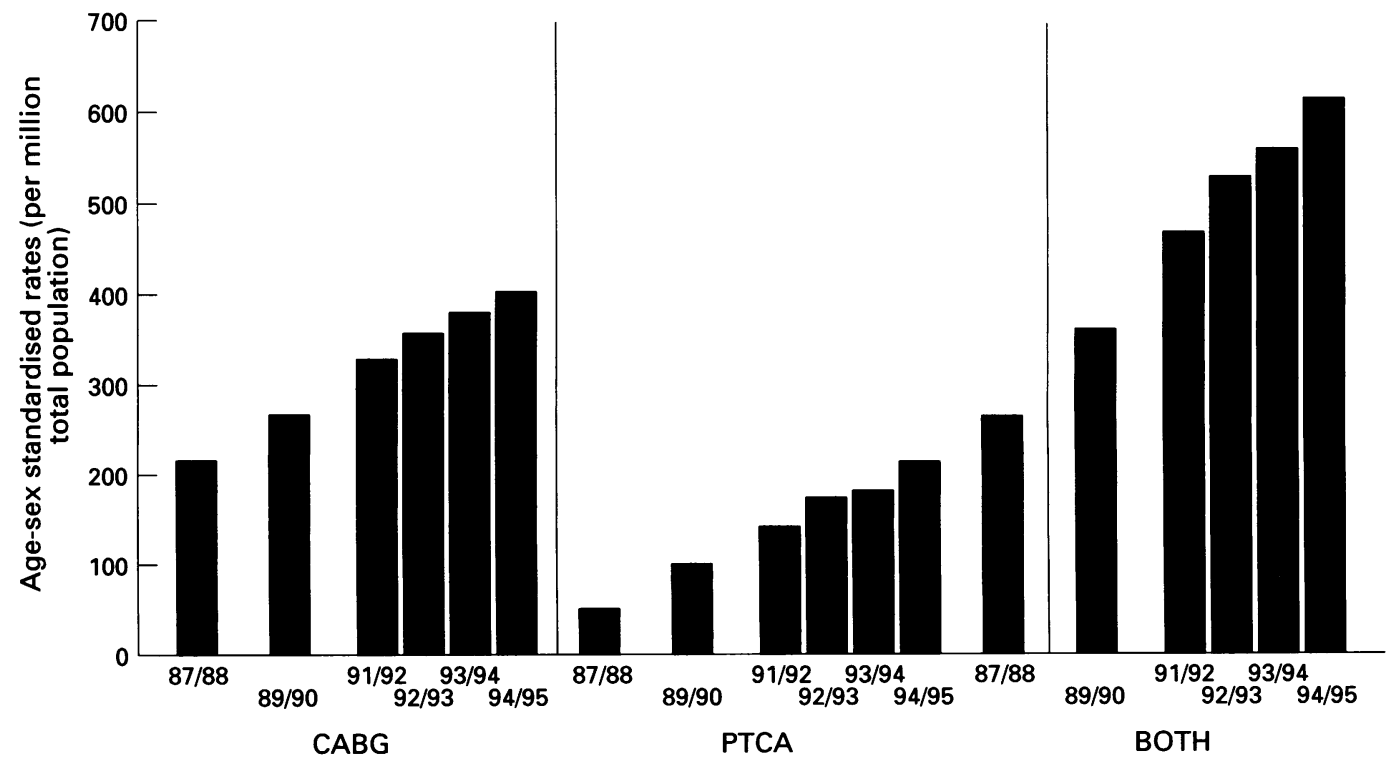


Figure 14 Age-sex standardised rates (per million total population) of $C A B G$ in the four study regions (1987/881994/95).

* Private provision for $S E$ Thames not included.
Figure 15 Age-sex standardised rates (per million total population) of $P T C A$ in the four study regions $(1987 / 88$ 1994/95).

*Private provision for $S E$ Thames not included.
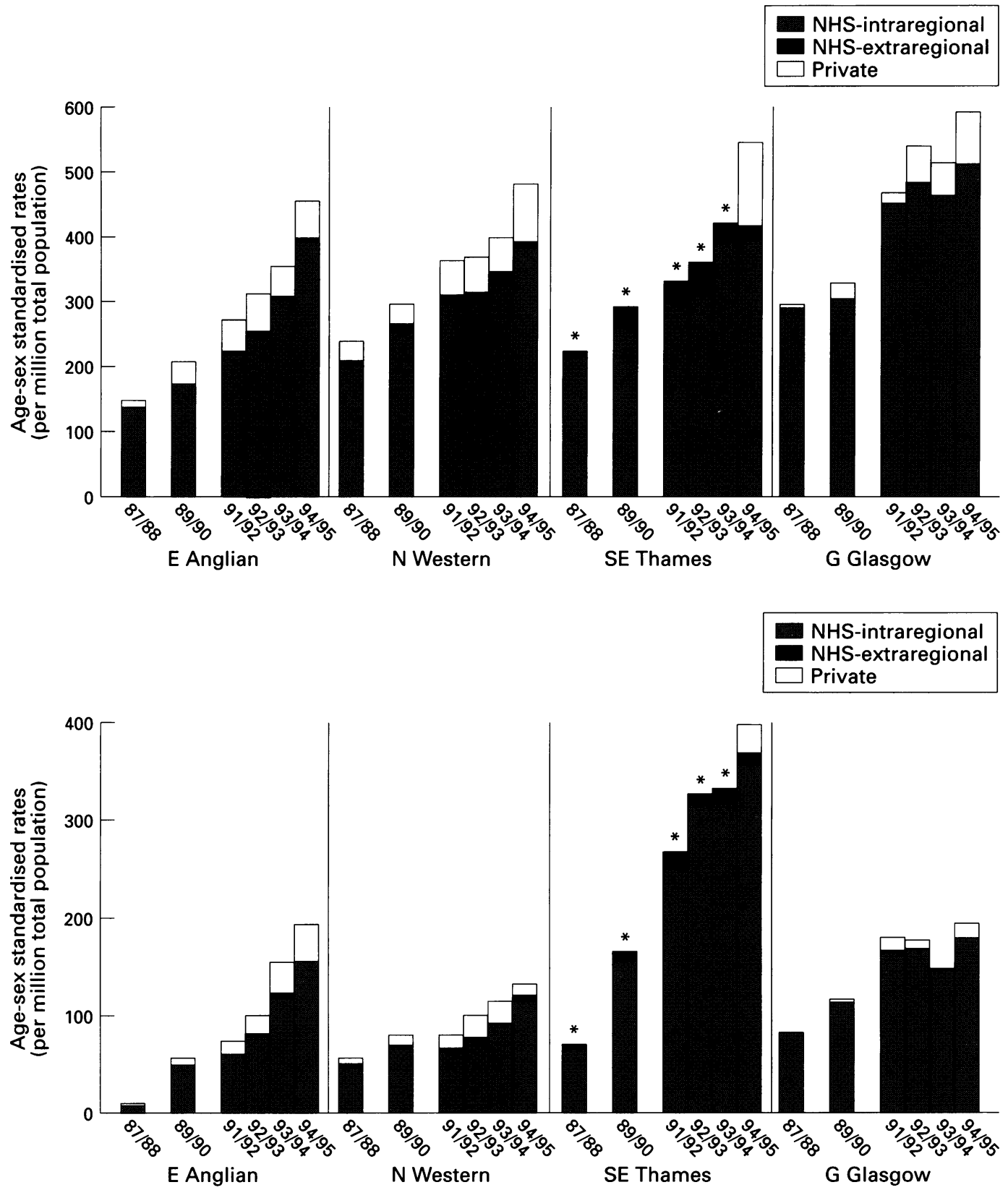

in North Western and 10.8 in South East Thames.

\section{USE OF SERVICES \\ Overall rates}

Trends in the NHS rate of CABG, PTCA and the two procedures combined are shown in fig 13. These data include all four study regions, which cover about $20 \%$ of the UK population. The rates of both procedures have risen steadily since $1987 / 88$. There is no evidence of PTCA slowing the growth of use of CABG. There is also no obvious impact of the 1991

Table 6 Annual increased (\%) in NHS rates (per million population) of CABG in the four study regions (1987/88 to 1994/95)

\begin{tabular}{lllll}
\hline & \multicolumn{4}{l}{ Region } \\
\cline { 2 - 5 } & E Anglian & N Western & SE Thames & G Glasgow \\
\hline $87 / 88-89 / 90$ & $12 \cdot 3$ & $14 \cdot 5$ & $14 \cdot 8$ & $2 \cdot 3$ \\
$89 / 90-91 / 92$ & $14 \cdot 6$ & $8 \cdot 5$ & $7 \cdot 3$ & $23 \cdot 3$ \\
$91 / 92-92 / 93$ & $16 \cdot 7$ & $1 \cdot 0$ & $7 \cdot 4$ & $6 \cdot 8$ \\
$92 / 93-93 / 94$ & $18 \cdot 9$ & $5 \cdot 7$ & $16 \cdot 9$ & $-4 \cdot 0$ \\
$93 / 94-94 / 95$ & $28 \cdot 2$ & $18 \cdot 6$ & $-0 \cdot 5$ & $10 \cdot 7$ \\
\hline
\end{tabular}

NHS reforms on the rates of use of these procedures, which have continued to increase in a linear fashion. Similar trends have been noted in other countries which have not undergone any reform of their health care systems (figs 1 and 2).

\section{Regional comparisons}

Trends in the regional rates for CABG and for PTCA are shown in figs 14 and 15 . The contributions of intraregional NHS, extraregional NHS, and private activity are shown. Comparison of the utilisation rates for the latest year for which complete data exist (1994/95) reveals significant inter-regional differences in NHS rates but considerably less than 1991/92. For CABG the rates vary only $1 \cdot 3$-fold from 395 per million (East Anglian and North Western) to 515 per million (Greater Glasgow) and for PTCA, threefold from 122 per million (North Western) to 371 per million (South East Thames). For three regions (East Anglian, North Western, Greater Glasgow) the PTCA rate was about $30-40 \%$ 
Figure 16 Age-sex standardised rates (per million aged $>24$ years) of $C A B G$ for residents of health districts and boards in the four study regions-

NHS cases only

(1987/88-1994/95).
Figure 17 Age-sex

standardised rates (per

million aged $>24$ years) of

PTCA for residents of

health districts and boards

in the four study regions-

NHS cases only

(1987/88-1994/95).
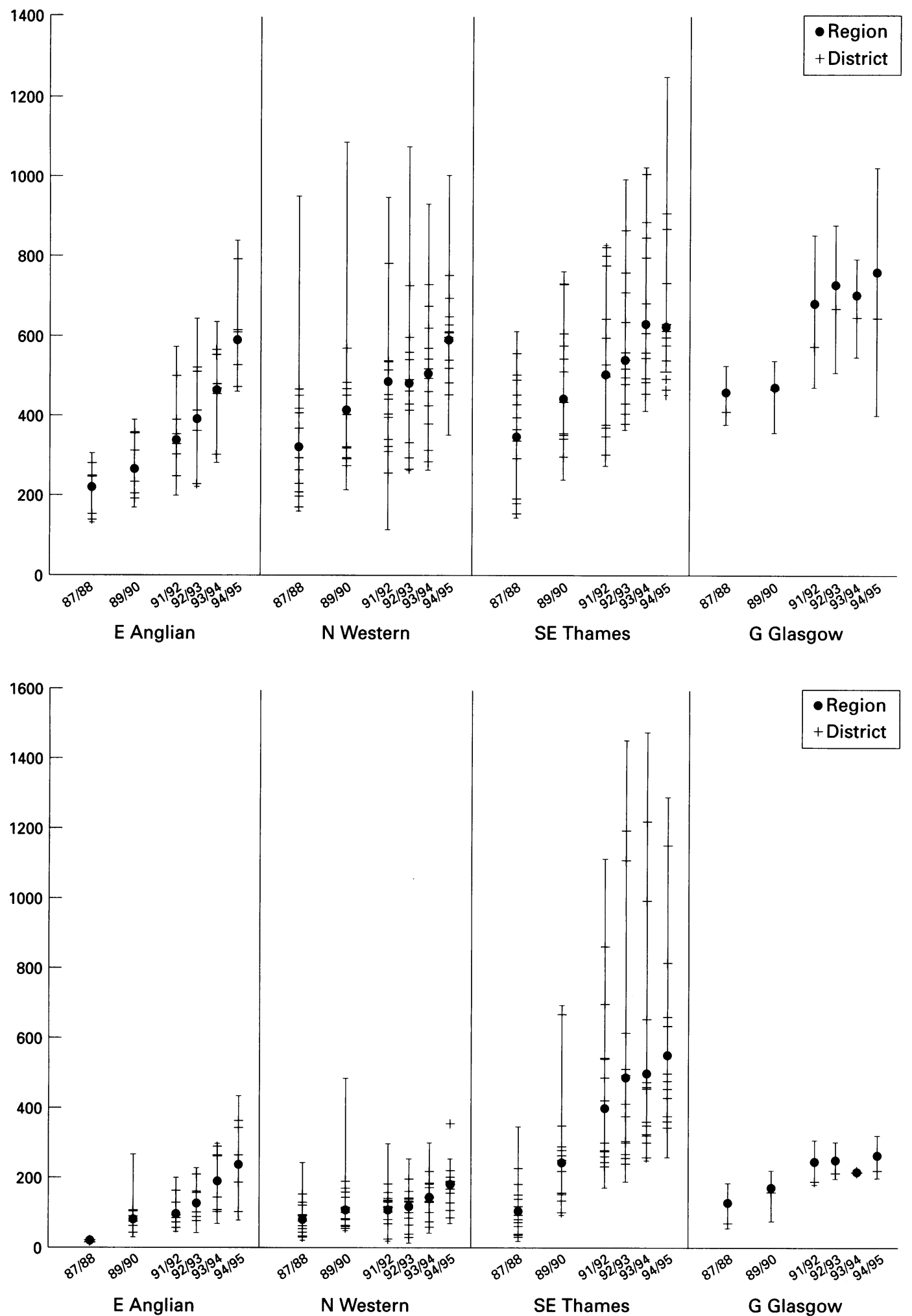

of the CABG rate. In contrast in South East Thames the rates of the two procedures were similar.

The NHS rates for both procedures increased (in some cases exponentially) in all four regions between 1987/88 and 1994/95. The extent of the increases in CABG was similar in three regions: Greater Glasgow (175\%), South East Thames (185\%), and North Western (191\%). The increase in East Anglian was greater (286\%) though starting from a lower rate. The annual rates of change over the seven years of the study are shown in table
6. Apart from East Anglian, where there has been a steady rise year-on-year, no clear pattern emerges for the other three regions. For example, Greater Glasgow appears to have experienced a stop-go policy with fluctuations from a $23 \%$ annual increase to a $4 \%$ decrease. For PTCA the increases generally were greater, partly because of the lower initial rates in 1987/88: Greater Glasgow (219\%), North Western (239\%), South East Thames (523\%), East Anglian (1963\%).

Most NHS cases of CABG were treated within the residents' region. The proportion of 
Table 7 Systematic component of variation (SCV) between district rates (NHS crude rates) of CABG and PTCA in the four study regions (1987/88-1994/95)

\begin{tabular}{|c|c|c|c|c|c|c|c|c|c|c|c|c|c|}
\hline & \multicolumn{6}{|l|}{$C A B G$} & \multicolumn{6}{|l|}{$P T C A$} & \multirow{2}{*}{$\frac{C A B G+P T C A}{94 / 95}$} \\
\hline & $87 / 88$ & $89 / 90$ & $91 / 92$ & $92 / 93$ & $93 / 94$ & $94 / 95$ & $87 / 88$ & $89 / 90$ & $91 / 92$ & $92 / 93$ & $93 / 94$ & $94 / 95$ & \\
\hline $\begin{array}{l}\text { E Anglian } \\
\text { N Western } \\
\text { SE Thames } \\
\text { G Glasgow }\end{array}$ & $\begin{array}{r}3 \cdot 8 \\
27 \cdot 3 \\
15 \cdot 7 \\
1 \cdot 7\end{array}$ & $\begin{array}{r}4 \cdot 7 \\
18 \cdot 8 \\
11 \cdot 1 \\
1.8\end{array}$ & $\begin{array}{r}5 \cdot 5 \\
13 \cdot 1 \\
9 \cdot 6 \\
5 \cdot 5\end{array}$ & $\begin{array}{r}5 \cdot 8 \\
12 \cdot 1 \\
5 \cdot 7 \\
6 \cdot 6\end{array}$ & $\begin{array}{l}3 \cdot 3 \\
8 \cdot 6 \\
6 \cdot 7 \\
1 \cdot 9\end{array}$ & $\begin{array}{r}1 \cdot 2 \\
4 \cdot 2 \\
8 \cdot 5 \\
11 \cdot 8\end{array}$ & $\begin{array}{l}\star \\
39.8 \\
50.1 \\
19.9\end{array}$ & $\begin{array}{l}55 \cdot 0 \\
56 \cdot 8 \\
47 \cdot 6 \\
11 \cdot 1\end{array}$ & $\begin{array}{r}14 \cdot 3 \\
24 \cdot 5 \\
36 \cdot 9 \\
4 \cdot 3\end{array}$ & $\begin{array}{r}18 \cdot 0 \\
60 \cdot 0 \\
50 \cdot 4 \\
2 \cdot 9\end{array}$ & $\begin{array}{r}16 \cdot 0 \\
10 \cdot 4 \\
44 \cdot 1 \\
0 \cdot 7\end{array}$ & $\begin{array}{r}15 \cdot 0 \\
9.5 \\
23.1 \\
2.8\end{array}$ & $\begin{array}{r}3 \cdot 1 \\
3 \cdot 6 \\
15 \cdot 0 \\
9 \cdot 1\end{array}$ \\
\hline
\end{tabular}

*Insufficient number of observations to give a reliable statistic.

cases treated outside the region in 1994/95 varied from none in Greater Glasgow to $5 \%$ in South East Thames. In contrast, there was more cross boundary flow for PTCA, from none in Greater Glasgow and East Anglian to $16 \%$ in South East Thames.

The contribution of private funding in 1994/95 also varied between the regions. For CABG the private contribution was $14 \%$ in Greater Glasgow, $15 \%$ in East Anglian, 17\% in North Western, and $23 \%$ in South East Thames. The proportions for PTCA were 7\% in North Western, $8 \%$ in Greater Glasgow and South East Thames, and $21 \%$ in East Anglian. The increase in the rate of private cases between 1987/88 and 1994/95 was greater than the increase in NHS cases (with the exception of PTCA in North Western): CABG-North Western $\times 2 \cdot 6$, East Anglian $\times 5 \cdot 2$, Greater Glasgow $\times 13 \cdot 5$; PTCAEast Anglian $\times 42$, North Western $\times 1 \cdot 8$. In

Table 8 Relation between district revascularisation rates and proxy measures of morbidity (correlation coefficients plus $95 \%$ confidence intervals)

\begin{tabular}{|c|c|c|c|}
\hline & $C A B G$ & $P T C A$ & Both \\
\hline $\begin{array}{l}S M R \\
1991 / 92 \\
1992 / 93 \\
1993 / 94 \\
1994 / 95\end{array}$ & $\begin{array}{l}-0.12(-0.40,0.19) \\
-0.18(-0.46,0.13) \\
-0.33(-0.58,-0.03) \\
-0.15(-0.44,0.16)\end{array}$ & $\begin{array}{l}-0.47(-0.67,-0.19) \\
-0.48(-0.68,-0.20) \\
-0.48(-0.69,-0.20) \\
-0.56(-0.74,-0.31)\end{array}$ & $\begin{array}{l}-0.35(-0.58,-0.09) \\
-0.42(-0.64,-0.13) \\
-0.45(-0.66,-0.17) \\
-0.45(-0.66,-0.17)\end{array}$ \\
\hline $\begin{array}{c}\text { Farman inde } \\
1992 / 93 \\
1993 / 94 \\
1994 / 95\end{array}$ & $\begin{array}{l}0.52(0.26,0.71) \\
0.18(-0.13,0.46) \\
0.12(-0.19,0.41)\end{array}$ & $\begin{array}{l}0.11(-0.20,0.40) \\
0.05(-0.26,0.35) \\
0.04(-0.27,0.34)\end{array}$ & $\begin{array}{l}0.30(-0.01,0.55) \\
0.11(-0.20,0.40) \\
0.08(-0.23,0.37)\end{array}$ \\
\hline $\begin{array}{r}\text { DoE index } \\
1992 / 93 \\
1993 / 94 \\
1994 / 95\end{array}$ & $\begin{array}{l}0.52(0.25,0.71) \\
0.21(-0.10,0.48) \\
0.08(-0.23,0.38)\end{array}$ & $\begin{array}{l}0.13(-0.18,0.42) \\
0.08(-0.23,0.37) \\
0.08(-0.23,0.38)\end{array}$ & $\begin{array}{l}0.31(0.01,0.56) \\
0.14(-0.18,0.42) \\
0.09(-0.22,0.38)\end{array}$ \\
\hline
\end{tabular}

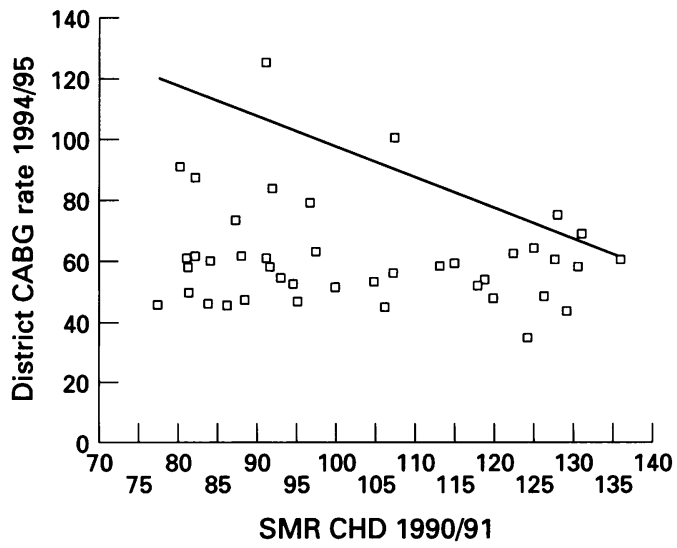

Figure 18 Relation between district utilisation rates for $C A B G$ (1994/95) and SMR values for coronary heart disease (CHD) 1990/91.
Greater Glasgow there was no consistent contribution from the private sector.

\section{District comparisons}

While the NHS CABG rate per million total population exceeded 300 in all four regions in $1993 / 94$ and $1994 / 95$, it was less than 300 per million in some districts and boards. This was true for 17 districts in 1992/93, 10 in 1993/94, and two in 1994/95. Only five districts met the more recent and more demanding targets of 450 CABG per million and 300 PTCA per million. A further five districts met the CABG target and a further four districts met the PTCA target. Detailed data on rates for intraregional NHS cases are shown in Appendix 2; for intraregional plus extraregional NHS cases in Appendix 3; for private cases in Appendix 4 (data for private cases in S.E. Thames were incomplete); and for NHS and private cases combined in Appendix 5.

The amount of variation in utilisation rates between districts within each region was, not surprisingly, even greater than the extent of inter-regional variation (figs 16 and 17). In $1994 / 95$ the district rate of CABG (funded by the NHS) varied 3.6-fold from 347 to 1254 per million aged over 24 years (232-840 per million total population) and the rate of PTCA varied 18-fold from 72 to 1297 per million (48-869 per million total population). Some of these differences arise from random variation. Generally speaking, the amount of interdistrict variation has fallen over the years (table 7). By 1994/95 there was only low variation in East Anglian and North Western. In South East Thames moderate variation persisted, while in Greater Glasgow a traditional low level of variation gave way to high variation in 1994/95. The latter occurred because the rate in Greater Glasgow Health Board increased by $25 \%$ and the rate in Lanarkshire decreased by $50 \%$. Variation in PTCA rates was far greater in the English regions, with high SCVs persisting in East Anglian and South East Thames, though there was only moderate variation in North Western. In contrast, variation was low in Greater Glasgow. When both procedures are considered together, the amount of variation is low in East Anglian and North Western, moderate in Greater Glasgow, and high in South East Thames.

It might have been thought that with the devolution of purchasing decisions from regions to districts and, to a modest extent, to GP fund holders, the amount of inter-regional and interdistrict variation would have increased. The fact that the opposite has hap- 
Table 9 Number of case notes that had to be searched for by hospital for $C A B G$ and $P T C A$

\begin{tabular}{|c|c|c|c|c|}
\hline \multirow[b]{2}{*}{ Hospital } & \multicolumn{2}{|l|}{$C A B G$} & \multicolumn{2}{|l|}{ PTCA } \\
\hline & $\begin{array}{l}\text { Number } \\
\text { sought }\end{array}$ & $\begin{array}{l}\text { Number } \\
\text { found }\end{array}$ & $\begin{array}{l}\text { Number } \\
\text { sought }\end{array}$ & $\begin{array}{l}\text { Number } \\
\text { found }\end{array}$ \\
\hline $\begin{array}{l}\text { Papworth } \\
\text { Kings } \\
\text { Guys } \\
\text { St Thomas' } \\
\text { Brook } \\
\text { Wythenshawe } \\
\text { Manchester RI } \\
\text { Victoria } \\
\text { Glasgow RI } \\
\text { Glasgow WI }\end{array}$ & $\begin{array}{l}78 \\
73 \\
409 \\
409 \\
85 \\
71 \\
78 \\
70 \\
71 \\
85\end{array}$ & $\begin{array}{l}70 \\
70 \\
35 \\
35 \\
70 \\
70 \\
70 \\
70 \\
70 \\
70\end{array}$ & $\begin{array}{c}77 \\
70 \\
\text { N/A } \\
\text { N/A } \\
86 \\
70 \\
66^{\star} \\
56 \\
70 \\
70\end{array}$ & $\begin{array}{r}70 \\
70 \\
\text { N/A } \\
\text { N/A } \\
70 \\
70 \\
60 \\
56 \\
70 \\
70\end{array}$ \\
\hline Overall & 691 & $\begin{array}{l}630 \\
(91 \%)\end{array}$ & 565 & $\begin{array}{l}535 \\
(95 \%)\end{array}$ \\
\hline
\end{tabular}

^Only 66 PTCAs undetaken at Manchester Royal Infirmary during period of study.

'Guy's Hospital and St Thomas' Hospital were treated as one provider and supplied 70 CABGs jointly. No PTCA data were provided.

pened might be a result of the NHS reforms. Alternatively it might reflect another long term trend-the spread of cardiology services to most district general hospitals-which has been unaffected by the reforms.

An earlier report found that in 1991/92 there was an inverse correlation between the district rate of coronary revascularisation and the standardised mortality ratio (SMR) for coronary heart disease for the district, taken as a proxy measure of need. ${ }^{14}$ Thus districts with the highest level of need had the lowest rates of revascularisation. Repeated analyses in subsequent years show that this relation has remained largely unchanged (table 8 , fig 18). Comparisons of district rates with two measures of social deprivation show a different picture. In 1992/93, the most deprived districts tended to have higher rates of revascularisation than more affluent ones. It was thought that

Table 10 Number of case notes with data on length of waiting periods for $C A B G$ $(n=630)$

\begin{tabular}{llllll}
\hline \multicolumn{5}{c}{ Waiting periods } \\
\cline { 2 - 6 } & $\begin{array}{l}\text { 1. Referral to } \\
\text { first cardiology } \\
\text { OP appt }\end{array}$ & $\begin{array}{l}\text { 2. First cardiology } \\
\text { OP appt to } \\
\text { angiogram }\end{array}$ & $\begin{array}{l}\text { 3. Angiogram } \\
\text { to be seen } \\
\text { by surgeon }\end{array}$ & $\begin{array}{l}\text { 4. Seen by } \\
\text { surgeon to } \\
\text { CABG }\end{array}$ & $\begin{array}{l}\text { 3+4. Angiogram } \\
\text { to CABG }\end{array}$ \\
\hline Papworth & 57 & 60 & 58 & 66 & 62 \\
Kings & 47 & 50 & 70 & 70 & 70 \\
Guys & 7 & 11 & 34 & 35 & 34 \\
St Thomas' & 30 & 33 & 35 & 35 & 35 \\
Brook & 14 & 16 & 70 & 70 & 70 \\
Wythenshawe & 53 & 61 & 67 & 67 & 70 \\
Manchester RI & 31 & 34 & 69 & 70 & 69 \\
Victoria & 15 & 16 & 64 & 65 & 69 \\
Glasgow RI & 40 & 62 & 66 & 66 & 70 \\
Glasgow WI & 34 & 34 & 70 & 70 & 70 \\
Overall & $328(52 \%)$ & $377(60 \%)$ & $603(96 \%)$ & $614(97 \%)$ & $619(98 \%)$ \\
\hline
\end{tabular}

Table 11 Number of case notes with data on length of waiting period for PTCA ( $n=536)$

\begin{tabular}{llll}
\hline & \multicolumn{3}{l}{ Waiting periods } \\
\cline { 2 - 4 } Hospital & $\begin{array}{l}\text { 1. Referral to first } \\
\text { cardiology OP appt }\end{array}$ & $\begin{array}{l}\text { 2. First cardiology OP } \\
\text { appt to angiogram }\end{array}$ & 3. Angiogram to PTCA \\
\hline Papworth & 68 & 68 & 70 \\
Kings & 51 & 53 & 70 \\
Brook & 25 & 29 & 70 \\
Wythenshawe & 53 & 62 & 70 \\
Manchester RI & 29 & 31 & 60 \\
Victoria & 21 & 21 & 55 \\
Glasgow RI & 51 & 61 & 70 \\
Glasgow WI & 32 & 32 & 70 \\
Overall & $330(62 \%)$ & $357(67 \%)$ & $535(100 \%)$ \\
\hline
\end{tabular}

part of the explanation might be the geographical proximity of the most deprived inner city districts to the tertiary hospitals carrying out the services. Since 1992/93 this correlation has largely disappeared. By 1994/95 there was no significant relation between deprivation and intervention rate. In other words, those districts with the greatest need (the most socially deprived) had intervention rates similar to those districts with the least need. In summary, in 1994/95 there was evidence both of the inverse care law (correlation with SMRs) and of no relation between rates and need.

\section{WAITING TIMES}

Data quality

Data on the waiting times experienced by patients in the 10 intraregional NHS hospitals in 1994/95 were collected. The intention was to collect data on the first 70 consecutive cases (both elective and emergency admissions) of each procedure from 1 April 1994. This was not possible for PTCA at hospitals $\mathrm{G}$ and $\mathrm{H}$ as only 66 and 56 such procedures respectively were undertaken during the first few months of the year. (Hospitals C and D were treated as a single institution so data were only provided on 35 patients in each. Both hospitals failed to provide data on their PTCA cases.) Overall, $91 \%$ of the case notes of CABG patients and $95 \%$ of those for PTCA patients were obtained and data abstracted. The proportion of notes found varied between the hospitals (table 9). When case notes were unobtainable the notes for the next consecutive patient treated, after the first 70 , were included.

Note that the times spent waiting by patients who were treated during the first half of a financial year may underestimate both the waiting times of patients treated later in the year and those on waiting lists but not fortunate enough to have been treated. It is also important that caution is exercised in interpreting the data too precisely, because of differences in the way cardiac services are organised in each hospital. For example, in some hospitals patients are first seen by a cardiologist in a district general hospital. Their first recorded appointment at the regional centre may then be on the same day as their angiogram, giving an appearance of not having had to wait.

Information on three waiting periods was derived from the data collected: from GP referral to the first cardiology outpatient appointment; from cardiology outpatients to coronary angiogram; and from angiogram to operative procedure (PTCA or CABG). For CABG patients the third period was also subdivided into the time from angiogram to first being seen by a surgeon, and from being seen by a surgeon to undergoing surgery.

Not surprisingly, not all the required dates could be found in the case notes. As a result, information on the different waiting periods was incomplete. For CABG, while the time from angiogram to surgery was available for $98 \%$ of patients, the time spent waiting for an initial appointment with a cardiologist was 
Table 12 Length of waiting periods (days) for CABG by hospital (all cases)

\begin{tabular}{|c|c|c|c|c|c|c|c|c|c|c|c|c|c|c|c|c|c|c|}
\hline \multirow[b]{3}{*}{ Hospital } & \multicolumn{18}{|c|}{ Waiting periods } \\
\hline & \multicolumn{3}{|c|}{$\begin{array}{l}\text { 1. Referral to first } \\
\text { cardiology OP appt }\end{array}$} & \multicolumn{3}{|c|}{$\begin{array}{l}\text { 2. First cardiology } O P \\
\text { appt to angiogram }\end{array}$} & \multicolumn{3}{|c|}{$\begin{array}{l}\text { 3. Angiogram to } \\
C A B G\end{array}$} & \multicolumn{3}{|c|}{$\begin{array}{l}\text { 3a. Angiogram to seen } \\
\text { by surgeon }\end{array}$} & \multicolumn{3}{|c|}{$\begin{array}{l}\text { 3b. Seen by surgeon to } \\
C A B G\end{array}$} & \multicolumn{3}{|c|}{ 4. Referral to $C A B G$} \\
\hline & Mean & $S D$ & Median & Mean & $S D$ & Median & Mean & $S D$ & Median & Mean & $S D$ & Median & Mean & $S D$ & Median & Mean & $S D$ & Median \\
\hline $\begin{array}{l}\text { Papworth } \\
\text { Kings } \\
\text { Guys } \\
\text { St Thomas } \\
\text { Brook } \\
\text { Wythenshawe } \\
\text { Manchester RI } \\
\text { Victoria } \\
\text { Glasgow RI } \\
\text { Glasgow WI }\end{array}$ & $\begin{array}{r}122 \cdot 6 \\
52 \cdot 7 \\
119 \cdot 1 \\
67 \cdot 8 \\
77 \cdot 3 \\
23 \cdot 6 \\
82 \cdot 0 \\
65 \cdot 4 \\
49 \cdot 7 \\
56 \cdot 9\end{array}$ & $\begin{array}{r}112 \cdot 5 \\
305 \cdot 5 \\
110 \cdot 4 \\
85 \cdot 2 \\
57 \cdot 5 \\
31 \cdot 7 \\
75 \cdot 4 \\
66 \cdot 2 \\
42 \cdot 8 \\
57 \cdot 7\end{array}$ & $\begin{array}{r}84 \cdot 0 \\
1.0 \\
74 \cdot 0 \\
39 \cdot 0 \\
66 \cdot 5 \\
14 \cdot 0 \\
71 \cdot 0 \\
26 \cdot 0 \\
43 \cdot 0 \\
41.5\end{array}$ & $\begin{array}{r}233 \cdot 3 \\
262 \cdot 4 \\
76 \cdot 4 \\
115 \cdot 0 \\
338 \cdot 7 \\
133 \cdot 8 \\
192 \cdot 0 \\
164 \cdot 2 \\
197 \cdot 6 \\
189 \cdot 0\end{array}$ & $\begin{array}{r}866 \cdot 5 \\
771 \cdot 0 \\
85 \cdot 2 \\
321 \cdot 9 \\
963 \cdot 6 \\
325 \cdot 0 \\
220 \cdot 7 \\
238 \cdot 3 \\
527 \cdot 9 \\
298 \cdot 8\end{array}$ & $\begin{array}{r}0 \cdot 5 \\
14 \cdot 4 \\
56 \cdot 0 \\
1 \cdot 0 \\
90 \cdot 0 \\
64 \cdot 0 \\
132 \cdot 5 \\
90 \cdot 0 \\
49 \cdot 5 \\
103 \cdot 0\end{array}$ & $\begin{array}{r}141 \cdot 2 \\
69 \cdot 6 \\
121 \cdot 8 \\
150 \cdot 6 \\
75 \cdot 2 \\
154 \cdot 6 \\
262 \cdot 9 \\
143 \cdot 9 \\
315 \cdot 6 \\
235 \cdot 6\end{array}$ & $\begin{array}{r}114 \cdot 6 \\
80 \cdot 3 \\
125 \cdot 9 \\
118 \cdot 1 \\
76 \cdot 7 \\
171 \cdot 4 \\
269 \cdot 6 \\
107 \cdot 3 \\
1298 \cdot 1 \\
124 \cdot 9\end{array}$ & $\begin{array}{r}137 \cdot 0 \\
35 \cdot 5 \\
73 \cdot 5 \\
152 \cdot 0 \\
49 \cdot 0 \\
82 \cdot 0 \\
206 \cdot 0 \\
135 \cdot 0 \\
160 \cdot 5 \\
245 \cdot 0\end{array}$ & $\begin{array}{r}17 \cdot 0 \\
23 \cdot 6 \\
44 \cdot 2 \\
36 \cdot 2 \\
8 \cdot 7 \\
29 \cdot 9 \\
49 \cdot 6 \\
41 \cdot 1 \\
213 \cdot 2 \\
53 \cdot 0\end{array}$ & $\begin{array}{r}43 \cdot 7 \\
28 \cdot 4 \\
67 \cdot 2 \\
32 \cdot 1 \\
31 \cdot 0 \\
49 \cdot 8 \\
101 \cdot 6 \\
49 \cdot 5 \\
1343 \cdot 9 \\
56 \cdot 7\end{array}$ & $\begin{array}{r}1 \cdot 0 \\
11.5 \\
17 \cdot 0 \\
39 \cdot 0 \\
0 \cdot 0 \\
7 \cdot 0 \\
8 \cdot 0 \\
27 \cdot 0 \\
29 \cdot 0 \\
38 \cdot 5\end{array}$ & $\begin{array}{r}124 \cdot 7 \\
46 \cdot 0 \\
78 \cdot 0 \\
114 \cdot 4 \\
66 \cdot 4 \\
129 \cdot 7 \\
214 \cdot 8 \\
111 \cdot 1 \\
120 \cdot 9 \\
182 \cdot 6\end{array}$ & $\begin{array}{r}112 \cdot 9 \\
64 \cdot 0 \\
90 \cdot 4 \\
100 \cdot 1 \\
68 \cdot 2 \\
149 \cdot 8 \\
229 \cdot 7 \\
90 \cdot 9 \\
86 \cdot 1 \\
105 \cdot 4\end{array}$ & $\begin{array}{r}109 \cdot 0 \\
12 \cdot 0 \\
48 \cdot 0 \\
111 \cdot 0 \\
39 \cdot 0 \\
69 \cdot 0 \\
166 \cdot 5 \\
114 \cdot 0 \\
130 \cdot 0 \\
195 \cdot 5\end{array}$ & $\begin{array}{l}376 \cdot 9 \\
380 \cdot 3 \\
364 \cdot 4 \\
338 \cdot 5 \\
517 \cdot 9 \\
300 \cdot 3 \\
580 \cdot 3 \\
393 \cdot 8 \\
431 \cdot 0 \\
479 \cdot 3\end{array}$ & $\begin{array}{r}565 \cdot 8 \\
878 \cdot 4 \\
195 \cdot 4 \\
349 \cdot 5 \\
1000 \cdot 4 \\
374 \cdot 9 \\
337 \cdot 9 \\
283 \cdot 6 \\
663 \cdot 0 \\
378 \cdot 5\end{array}$ & $\begin{array}{r}273 \cdot 0 \\
34 \cdot 0 \\
380 \cdot 5 \\
300 \cdot 5 \\
273 \cdot 0 \\
205 \cdot 0 \\
442 \cdot 5 \\
349 \cdot 0 \\
263 \cdot 0 \\
375 \cdot 0\end{array}$ \\
\hline Overall & $67 \cdot 4$ & $136 \cdot 8$ & $36 \cdot 0$ & $194 \cdot 1$ & $566 \cdot 7$ & $35 \cdot 0$ & $170 \cdot 9$ & $461 \cdot 6$ & $123 \cdot 0$ & $52 \cdot 8$ & $448 \cdot 5$ & $13 \cdot 0$ & $121 \cdot 4$ & $131 \cdot 0$ & $87 \cdot 0$ & $405 \cdot 4$ & $568 \cdot 0$ & $281 \cdot 0$ \\
\hline$P$ value & \multicolumn{3}{|c|}{0.000001} & \multicolumn{3}{|c|}{0.000001} & \multicolumn{3}{|c|}{0.0293} & \multicolumn{3}{|c|}{$0 \cdot 000001$} & \multicolumn{3}{|c|}{0.000001} & \multicolumn{2}{|r|}{0.6463} & \\
\hline
\end{tabular}

Table 13 Length of waiting periods (days) for CABG by hospital (excluding 10\% waits)

\begin{tabular}{|c|c|c|c|c|c|c|c|c|c|c|c|c|c|c|c|c|c|c|}
\hline \multirow[b]{3}{*}{ Hospital } & \multicolumn{18}{|c|}{ Waiting periods } \\
\hline & \multicolumn{3}{|c|}{$\begin{array}{l}\text { 1. Referral to first } \\
\text { cardiology OP appt }\end{array}$} & \multicolumn{3}{|c|}{$\begin{array}{l}\text { 2. First cardiology } O P \\
\text { appt to angiogram }\end{array}$} & \multicolumn{3}{|c|}{$\begin{array}{l}\text { 3. Angiogram to } \\
C A B G\end{array}$} & \multicolumn{3}{|c|}{$\begin{array}{l}\text { 3a. Angiogram to } \\
\text { seen by surgeon }\end{array}$} & \multicolumn{3}{|c|}{$\begin{array}{l}\text { 3b. Seen by surgeon } \\
\text { to } C A B G\end{array}$} & \multicolumn{3}{|c|}{ 4. Referral to $C A B G$} \\
\hline & Mean & $S D$ & Median & Mean & $S D$ & Median & Mean & $S D$ & Median & Mean & $S D$ & Median & Mean & $S D$ & Median & Mean & $S D$ & Median \\
\hline $\begin{array}{l}\text { Papworth } \\
\text { Kings } \\
\text { Guys } \\
\text { St Thomas } \\
\text { Brook } \\
\text { Wythenshawe } \\
\text { Manchester RI } \\
\text { Victoria } \\
\text { Glasgow RI } \\
\text { Glasgow WI }\end{array}$ & $\begin{array}{r}48 \cdot 8 \\
8 \cdot 2 \\
67 \cdot 0 \\
35 \cdot 0 \\
65 \cdot 2 \\
20 \cdot 3 \\
65 \cdot 9 \\
65 \cdot 4 \\
49 \cdot 7 \\
44 \cdot 0\end{array}$ & $\begin{array}{l}42 \cdot 1 \\
15 \cdot 4 \\
64 \cdot 6 \\
40 \cdot 1 \\
36 \cdot 8 \\
21 \cdot 1 \\
39 \cdot 6 \\
66 \cdot 2 \\
42 \cdot 8 \\
24 \cdot 8\end{array}$ & $\begin{array}{r}36 \cdot 0 \\
1 \cdot 0 \\
63 \cdot 0 \\
17 \cdot 0 \\
65 \cdot 0 \\
12 \cdot 0 \\
70 \cdot 0 \\
26 \cdot 0 \\
43 \cdot 0 \\
40 \cdot 0\end{array}$ & $\begin{array}{r}2 \cdot 4 \\
39 \cdot 5 \\
76 \cdot 4 \\
29 \cdot 7 \\
81 \cdot 1 \\
71 \cdot 2 \\
125 \cdot 3 \\
110 \cdot 2 \\
49 \cdot 6 \\
91 \cdot 2\end{array}$ & $\begin{array}{r}10 \cdot 9 \\
81 \cdot 4 \\
85 \cdot 1 \\
57 \cdot 4 \\
81 \cdot 5 \\
67 \cdot 4 \\
96 \cdot 0 \\
104 \cdot 3 \\
45 \cdot 9 \\
61 \cdot 2\end{array}$ & $\begin{array}{r}0.0 \\
4 \cdot 0 \\
56 \cdot 0 \\
0.5 \\
74 \cdot 0 \\
67 \cdot 5 \\
118 \cdot 0 \\
85 \cdot 0 \\
40 \cdot 0 \\
89 \cdot 0\end{array}$ & $\begin{array}{r}129 \cdot 0 \\
64 \cdot 7 \\
105 \cdot 1 \\
129 \cdot 9 \\
75 \cdot 2 \\
91 \cdot 6 \\
106 \cdot 7 \\
141 \cdot 0 \\
150 \cdot 3 \\
188 \cdot 2\end{array}$ & $\begin{array}{r}103 \cdot 0 \\
69 \cdot 4 \\
109 \cdot 4 \\
100 \cdot 4 \\
76 \cdot 7 \\
96 \cdot 3 \\
109 \cdot 4 \\
105 \cdot 4 \\
96 \cdot 5 \\
96 \cdot 4\end{array}$ & $\begin{array}{r}133 \cdot 0 \\
35.0 \\
53.5 \\
111.0 \\
49 \cdot 0 \\
68 \cdot 5 \\
59 \cdot 5 \\
135 \cdot 0 \\
156 \cdot 0 \\
206.5\end{array}$ & $\begin{array}{r}8 \cdot 7 \\
18 \cdot 7 \\
22 \cdot 9 \\
30 \cdot 9 \\
2 \cdot 5 \\
16 \cdot 6 \\
15 \cdot 3 \\
29 \cdot 3 \\
23 \cdot 5 \\
35 \cdot 4\end{array}$ & $\begin{array}{r}18 \cdot 9 \\
20 \cdot 5 \\
28 \cdot 7 \\
23 \cdot 1 \\
8 \cdot 1 \\
22 \cdot 1 \\
20 \cdot 8 \\
22 \cdot 3 \\
22 \cdot 9 \\
24 \cdot 5\end{array}$ & $\begin{array}{r}1 \cdot 0 \\
7 \cdot 5 \\
2 \cdot 0 \\
35 \cdot 0 \\
0 \cdot 0 \\
3 \cdot 0 \\
5 \cdot 0 \\
26 \cdot 0 \\
14 \cdot 0 \\
32 \cdot 0\end{array}$ & $\begin{array}{r}99 \cdot 4 \\
42 \cdot 5 \\
63 \cdot 6 \\
95 \cdot 0 \\
66 \cdot 4 \\
62 \cdot 8 \\
92 \cdot 6 \\
102 \cdot 5 \\
112 \cdot 7 \\
153 \cdot 3\end{array}$ & $\begin{array}{l}89 \cdot 1 \\
57 \cdot 1 \\
70 \cdot 0 \\
80 \cdot 1 \\
68 \cdot 2 \\
70 \cdot 7 \\
99 \cdot 4 \\
83 \cdot 8 \\
79 \cdot 2 \\
80 \cdot 2\end{array}$ & $\begin{array}{r}86 \cdot 0 \\
11 \cdot 0 \\
32 \cdot 0 \\
93 \cdot 0 \\
39 \cdot 0 \\
43 \cdot 0 \\
32 \cdot 0 \\
90 \cdot 0 \\
121 \cdot 0 \\
179 \cdot 5\end{array}$ & $\begin{array}{l}272 \cdot 9 \\
101 \cdot 0 \\
364 \cdot 4 \\
259 \cdot 3 \\
253 \cdot 6 \\
230 \cdot 2 \\
379 \cdot 3 \\
339 \cdot 7 \\
247 \cdot 7 \\
364 \cdot 2\end{array}$ & $\begin{array}{l}202 \cdot 2 \\
164 \cdot 7 \\
195 \cdot 4 \\
169 \cdot 3 \\
157 \cdot 1 \\
198 \cdot 6 \\
189 \cdot 0 \\
198 \cdot 3 \\
186 \cdot 5 \\
134 \cdot 3\end{array}$ & $\begin{array}{r}241 \cdot 0 \\
21 \cdot 5 \\
380 \cdot 5 \\
282 \cdot 0 \\
268 \cdot 0 \\
189 \cdot 5 \\
384 \cdot 5 \\
315 \cdot 0 \\
230 \cdot 0 \\
352 \cdot 0\end{array}$ \\
\hline Overall & $39 \cdot 4$ & $40 \cdot 5$ & $28 \cdot 0$ & $57 \cdot 8$ & $74 \cdot 7$ & $26 \cdot 0$ & $116 \cdot 8$ & $101 \cdot 5$ & $96 \cdot 0$ & $19 \cdot 5$ & $23 \cdot 2$ & $7 \cdot 0$ & $89 \cdot 3$ & $83 \cdot 6$ & $68 \cdot 0$ & $259 \cdot 7$ & $197 \cdot 2$ & $246 \cdot 0$ \\
\hline$P$ value & \multicolumn{3}{|c|}{$<0.000001$} & \multicolumn{3}{|c|}{$<0.000001$} & \multicolumn{3}{|c|}{$<0.000001$} & \multicolumn{3}{|c|}{$<0.000001$} & \multicolumn{3}{|c|}{$<0.000001$} & \multicolumn{3}{|c|}{$<0.000001$} \\
\hline
\end{tabular}

only available for $52 \%$ of cases (table 10) Information retrieval for PTCA cases was better (table 11). One reason why information on the first two waiting periods was incomplete was that some patients were admitted as emergencies or were transferred from another hospital and therefore did not attend a cardiology outpatient clinic. The other reasons for incomplete data were loss of the GP's referral letter and no record having been made in the case notes of the date the coronary angiogram was performed or the date first seen by a surgeon. This means that information on the time spent waiting to first see a cardiologist and waiting for an angiogram reflect the experience of those referred by GPs and excludes emergency admissions and transfers. In contrast, the time spent waiting for CABG or PTCA after having had an angiogram includes both GP referrals and emergency admissions.
Waiting times for all cases

The mean length of each waiting period both overall and for each hospital is shown for CABG in table 12. There was enormous variation between patients, an indication of which is provided by the standard deviation (SD). The overall (all hospitals) means for the three time periods were 67, 194, and 171 days. There was significant variation between the hospitals for differences in the time spent waiting for a first cardiology appointment. The third period (angiogram to CABG) was divided into two components: (1) from angiogram to being seen by a surgeon (mean $=53$ days); (2) from being seen by a surgeon to $\mathrm{CABG}$ (mean $=121$ days). Again, these time periods varied significantly between hospitals. The final column in table 12 shows the overall time for those patients referred by their GP (mean $=405$ days). The reason that this

Table 14 Length of waiting periods (days) for PTCA by hospital (all cases)

\begin{tabular}{|c|c|c|c|c|c|c|c|c|c|c|c|c|}
\hline \multirow[b]{3}{*}{ Hospital } & \multicolumn{12}{|c|}{ Waiting periods } \\
\hline & \multicolumn{3}{|c|}{$\begin{array}{l}\text { 1. Referral to first } \\
\text { cardiology OP appt }\end{array}$} & \multicolumn{3}{|c|}{$\begin{array}{l}\text { 2. First cardiology } O P \\
\text { appt to angiogram }\end{array}$} & \multicolumn{3}{|c|}{ 3. Angiogram to $P T C A$} & \multicolumn{3}{|c|}{ 4. Referral to PTCA } \\
\hline & Mean & $S D$ & Median & Mean & $S D$ & Median & Mean & $S D$ & Median & Mean & $S D$ & Median \\
\hline $\begin{array}{l}\text { Papworth } \\
\text { Kings } \\
\text { Brook } \\
\text { Wythenshawe } \\
\text { Manchester RI } \\
\text { Victoria } \\
\text { Glasgow RI } \\
\text { Glasgow WI }\end{array}$ & $\begin{array}{r}76.9 \\
7.9 \\
183.6 \\
30.0 \\
41.0 \\
82.3 \\
58.6 \\
77.0\end{array}$ & $\begin{array}{r}105 \cdot 5 \\
21 \cdot 3 \\
316 \cdot 2 \\
23 \cdot 6 \\
67 \cdot 5 \\
63 \cdot 6 \\
92 \cdot 8 \\
200 \cdot 3\end{array}$ & $\begin{array}{r}28 \cdot 5 \\
0.0 \\
65 \cdot 0 \\
27 \cdot 0 \\
8 \cdot 0 \\
72 \cdot 0 \\
42 \cdot 0 \\
39 \cdot 5\end{array}$ & $\begin{array}{r}250 \cdot 5 \\
17 \cdot 0 \\
526 \cdot 2 \\
118 \cdot 1 \\
272 \cdot 2 \\
196 \cdot 4 \\
172 \cdot 2 \\
270 \cdot 5\end{array}$ & $\begin{array}{r}738 \cdot 5 \\
43 \cdot 1 \\
886 \cdot 6 \\
163 \cdot 5 \\
445 \cdot 2 \\
217 \cdot 1 \\
356 \cdot 4 \\
685 \cdot 1\end{array}$ & $\begin{array}{r}1.0 \\
0.0 \\
120 \cdot 0 \\
61 \cdot 0 \\
64.0 \\
132.0 \\
69 \cdot 0 \\
104.5\end{array}$ & $\begin{array}{l}21 \cdot 5 \\
12 \cdot 4 \\
59 \cdot 3 \\
63 \cdot 6 \\
70 \cdot 0 \\
76 \cdot 0 \\
64 \cdot 6 \\
76 \cdot 8\end{array}$ & $\begin{array}{l}38 \cdot 7 \\
30 \cdot 4 \\
99 \cdot 9 \\
67 \cdot 8 \\
89 \cdot 9 \\
68 \cdot 5 \\
57 \cdot 3 \\
72 \cdot 3\end{array}$ & $\begin{array}{r}1 \cdot 0 \\
0 \cdot 0 \\
35 \cdot 0 \\
41 \cdot 0 \\
32 \cdot 5 \\
69 \cdot 0 \\
64 \cdot 6 \\
70 \cdot 0\end{array}$ & $\begin{array}{r}358 \cdot 9 \\
35 \cdot 1 \\
679 \cdot 9 \\
212 \cdot 8 \\
411 \cdot 1 \\
375 \cdot 3 \\
296 \cdot 2 \\
443 \cdot 8\end{array}$ & $\begin{array}{r}743 \cdot 2 \\
91 \cdot 4 \\
910 \cdot 9 \\
190 \cdot 2 \\
567 \cdot 4 \\
257 \cdot 7 \\
398 \cdot 4 \\
690 \cdot 7\end{array}$ & $\begin{array}{r}134 \cdot 0 \\
1 \cdot 0 \\
283 \cdot 0 \\
187 \cdot 0 \\
197 \cdot 0 \\
294 \cdot 0 \\
189 \cdot 0 \\
238 \cdot 5\end{array}$ \\
\hline Overall & $61 \cdot 2$ & $131 \cdot 6$ & $28 \cdot 0$ & $198 \cdot 2$ & 522.5 & $43 \cdot 0$ & $58 \cdot 4$ & $73 \cdot 1$ & $37 \cdot 0$ & $314 \cdot 0$ & $554 \cdot 9$ & $177 \cdot 0$ \\
\hline$P$ value & \multicolumn{3}{|c|}{0.000001} & \multicolumn{3}{|c|}{0.000001} & \multicolumn{3}{|c|}{0.000001} & \multicolumn{3}{|c|}{0.000001} \\
\hline
\end{tabular}


Table 15 Length of waiting periods (days) for PTCA by hospital (excluding 10\% longest waits)

\begin{tabular}{|c|c|c|c|c|c|c|c|c|c|c|c|c|}
\hline \multirow[b]{3}{*}{ Hospital } & \multicolumn{12}{|c|}{ Waiting periods } \\
\hline & \multicolumn{3}{|c|}{$\begin{array}{l}\text { 1. Referral to first } \\
\text { cardiology OP appt }\end{array}$} & \multicolumn{3}{|c|}{$\begin{array}{l}\text { 2. First cardiology } O P \\
\text { appt to angiogram }\end{array}$} & \multicolumn{3}{|c|}{ 3. Angiogram to $P T C A$} & \multicolumn{3}{|c|}{ 4. Referral to $P T C A$} \\
\hline & Mean & $S D$ & Median & Mean & $S D$ & Median & Mean & $S D$ & Median & Mean & $S D$ & Median \\
\hline $\begin{array}{l}\text { Papworth } \\
\text { Kings } \\
\text { Brook } \\
\text { Wythenshawe } \\
\text { Manchester RI } \\
\text { Victoria } \\
\text { Glasgow RI } \\
\text { Glasgow WI }\end{array}$ & $\begin{array}{r}29 \cdot 9 \\
5 \cdot 4 \\
56 \cdot 8 \\
28 \cdot 2 \\
20 \cdot 2 \\
62 \cdot 7 \\
40 \cdot 2 \\
42 \cdot 0\end{array}$ & $\begin{array}{l}32 \cdot 6 \\
12.0 \\
39 \cdot 6 \\
19 \cdot 7 \\
26.6 \\
33.4 \\
29 \cdot 1 \\
30.9\end{array}$ & $\begin{array}{r}19 \cdot 0 \\
0.0 \\
58 \cdot 0 \\
26 \cdot 5 \\
6 \cdot 5 \\
71 \cdot 0 \\
40 \cdot 0 \\
37 \cdot 0\end{array}$ & $\begin{array}{r}50 \cdot 1 \\
17 \cdot 0 \\
89 \cdot 2 \\
84 \cdot 4 \\
56 \cdot 3 \\
137 \cdot 9 \\
69 \cdot 9 \\
102 \cdot 2\end{array}$ & $\begin{array}{r}94 \cdot 8 \\
43 \cdot 1 \\
80 \cdot 3 \\
75 \cdot 1 \\
76 \cdot 3 \\
105 \cdot 3 \\
75 \cdot 7 \\
77 \cdot 2\end{array}$ & $\begin{array}{r}1 \cdot 0 \\
0 \cdot 0 \\
78 \cdot 0 \\
51 \cdot 0 \\
8 \cdot 0 \\
128 \cdot 0 \\
65 \cdot 0 \\
65 \cdot 0\end{array}$ & $\begin{array}{r}19 \cdot 5 \\
9 \cdot 3 \\
36 \cdot 6 \\
46 \cdot 1 \\
32 \cdot 5 \\
56 \cdot 2 \\
51 \cdot 0 \\
54 \cdot 5\end{array}$ & $\begin{array}{l}35 \cdot 1 \\
15 \cdot 7 \\
39 \cdot 7 \\
35 \cdot 4 \\
39 \cdot 0 \\
44 \cdot 1 \\
40 \cdot 1 \\
40 \cdot 3\end{array}$ & $\begin{array}{r}1 \cdot 0 \\
0 \cdot 0 \\
18 \cdot 0 \\
37 \cdot 0 \\
15 \cdot 0 \\
55 \cdot 0 \\
49 \cdot 0 \\
62 \cdot 0\end{array}$ & $\begin{array}{r}159 \cdot 5 \\
35 \cdot 1 \\
214 \cdot 8 \\
184 \cdot 2 \\
167 \cdot 2 \\
285 \cdot 0 \\
185 \cdot 5 \\
249 \cdot 5\end{array}$ & $\begin{array}{r}170 \cdot 1 \\
91 \cdot 4 \\
136 \cdot 4 \\
113 \cdot 2 \\
182 \cdot 4 \\
127 \cdot 6 \\
131 \cdot 5 \\
128 \cdot 6\end{array}$ & $\begin{array}{r}90 \cdot 0 \\
1.0 \\
193 \cdot 5 \\
182 \cdot 0 \\
128 \cdot 0 \\
286 \cdot 0 \\
178 \cdot 0 \\
234 \cdot 0\end{array}$ \\
\hline Overall & $31 \cdot 3$ & $31 \cdot 3$ & $23 \cdot 0$ & $66 \cdot 5$ & $81 \cdot 8$ & $30 \cdot 5$ & $39 \cdot 9$ & $39 \cdot 9$ & $30 \cdot 5$ & $166 \cdot 8$ & $151 \cdot 2$ & $142 \cdot 0$ \\
\hline$P$ value & \multicolumn{3}{|c|}{$<0.000001$} & \multicolumn{3}{|c|}{$<0.000001$} & \multicolumn{3}{|c|}{$<0.000001$} & \multicolumn{3}{|c|}{$<0.000001$} \\
\hline
\end{tabular}

figure is less than the summation of the mean of the three component periods is because each mean is based on different groups of patients depending on data available in the case notes.

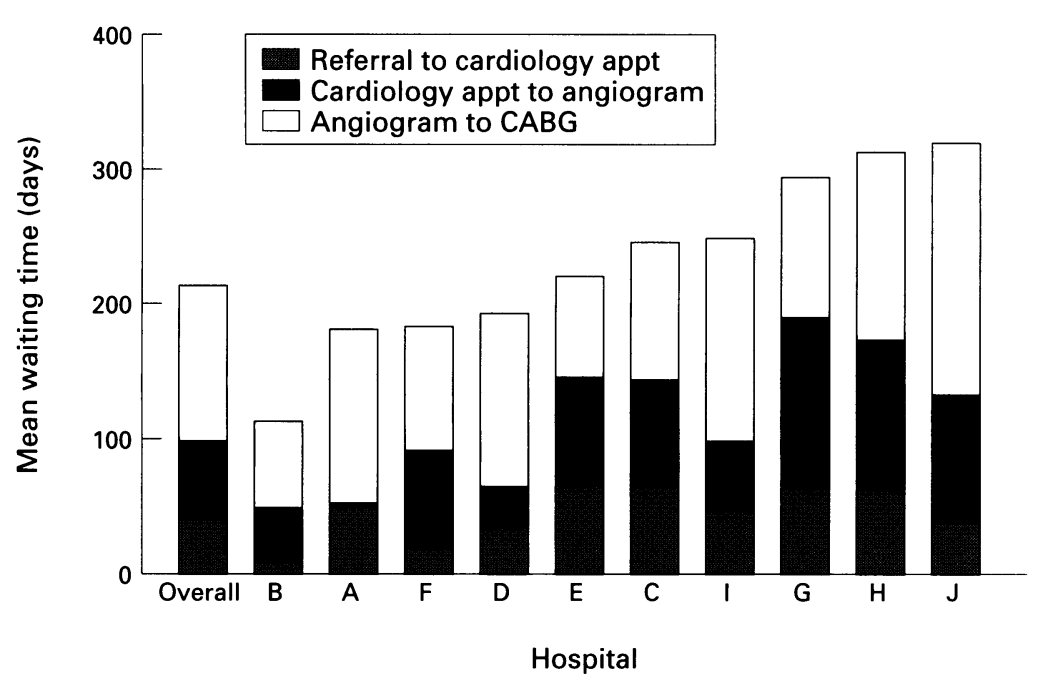

Figure 19 Mean waiting times (days) for CABG 1994/95, overall and by hospital (excluding $10 \%$ longest waits).

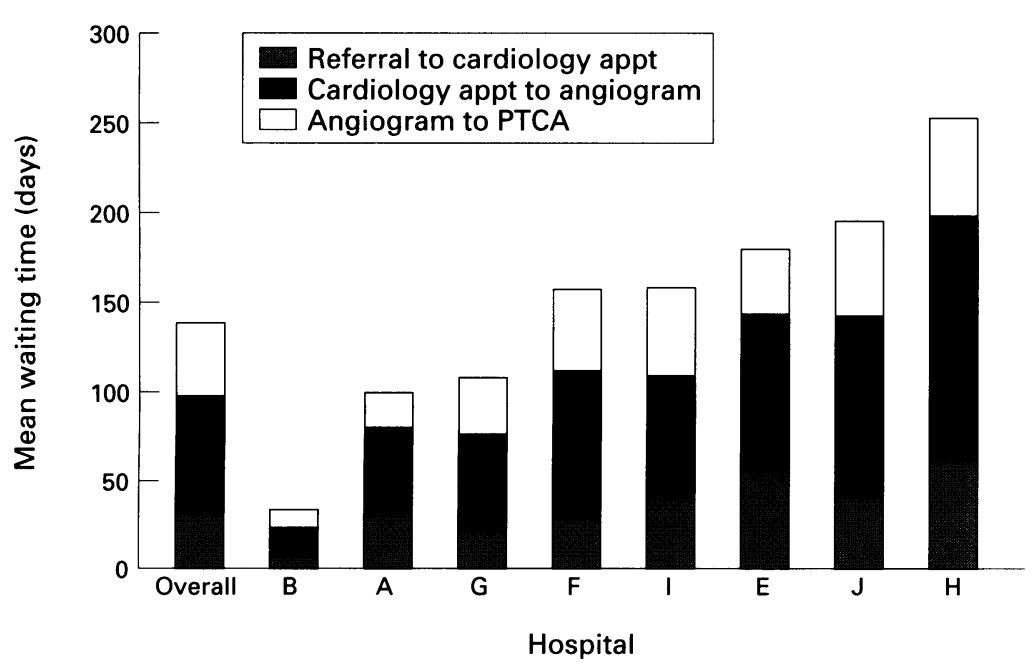

Figure 20 Mean waiting times (days) for PTCA 1994/95, overall and by hospital (excluding $10 \%$ longest waits).
Waiting times excluding long waits

The median waiting times are generally much lower than the means because the latter are unduly influenced by a small number of patients who wait (or appear to wait) an inordinately long time. In practice, some of these patients are not waiting. For example, a patient may be managed by a cardiologist for several years before it is felt appropriate to carry out a coronary angiogram. Yet this patient would appear to have a very long wait between first being seen by a cardiologist and undergoing an angiogram. To exclude the influence of such cases, the data were also analysed having first excluded the $10 \%$ of patients who had the longest time periods (table 13).

Having excluded the $10 \%$ of patients with the longest waits, the mean waiting time to see a cardiologist was 39 days (interhospital range $=8$ to 67 days; $\mathrm{P}<0.00001)$; to have an angiogram was 58 days (2 to 125 days; $P<0.00001)$; and to undergo surgery was 117 days (65 to 188 days; $\mathrm{P}<0.00001$ ). These data are shown in fig 19 in which hospitals are ranked by the length of time from referral to CABG. The major contribution to the overall waiting time was the time spent waiting for surgery after an angiogram. Most of this time (89 days) was spent waiting for surgery after being seen by a surgeon.

Similar data for PTCA are shown in tables 14 and 15 . Having excluded the $10 \%$ longest waits, the overall mean waiting times were 31 days for a cardiology appointment, 67 days for an angiogram, and 40 days for PTCA (table 15). As with $C A B G$, significant interhospital variation existed for all three waiting periods. Unlike CABG, the waiting time for an angiogram was the principal contributor to the overall wait (fig 20).

\section{Trends over time}

Waiting times (for truncated data) in 1994/95 were compared with those in 1992/93. The waiting time from referral to $\mathrm{CABG}$ was largely unchanged for all 10 hospitals overall (fig 21)-234 days in 1992/93 compared with 214 days in 1994/95. There was no significant change in the mean lengths of the three principal constituent waits. Despite this some of the hospitals showed significant changes between the two assessment periods. For example, the 


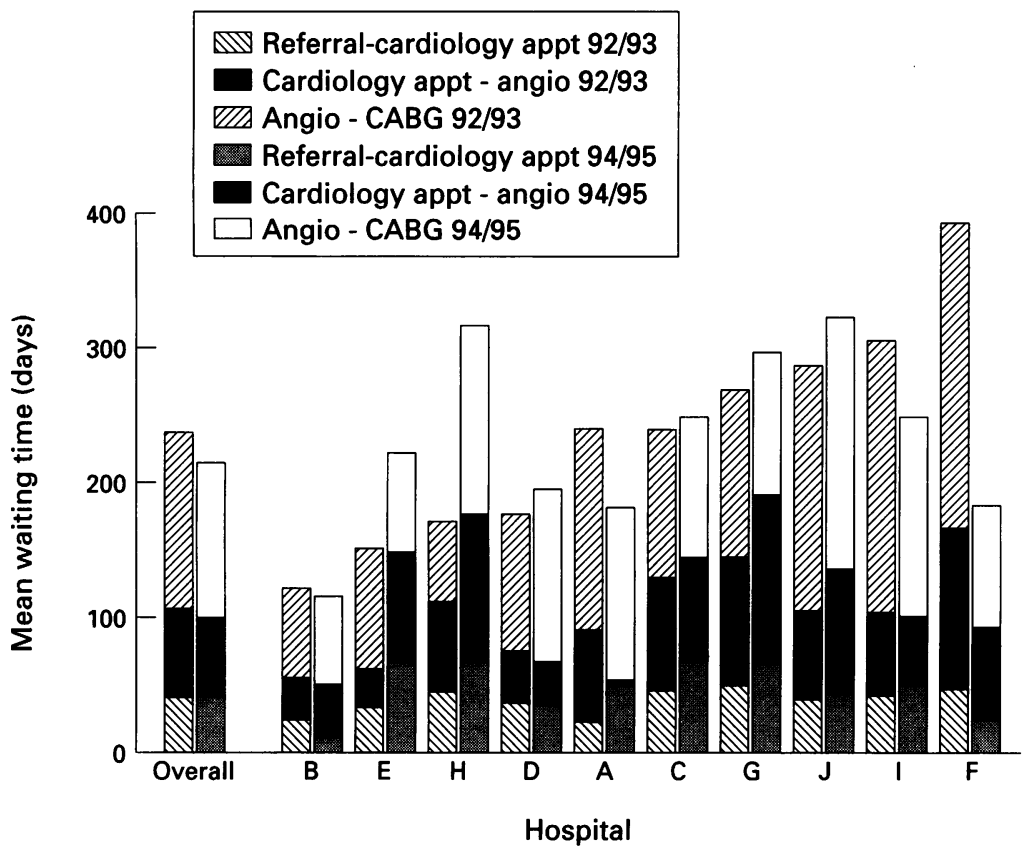

Figure 21 Mean waiting times (days) for CABG 1992/93 and 1994/95, overall and by hospital (excluding 10\% longest waits).

waiting time in hospital $\mathrm{F}$ fell dramatically whereas in hospitals $\mathrm{E}$ and $\mathrm{H}$ it rose.

The waiting time from referral to PTCA was $25 \%$ shorter for all eight hospitals overall (fig 22) - 185 days in 1992/93 compared with 138 days in 1994/95. Reductions had occurred in all three principal constituent waiting periods. While waiting time had decreased in five of the hospitals, it had risen in three, by as much as $76 \%$ in hospital $\mathrm{H}$.

One of the early characteristics of contracts for coronary revascularisation has been purchasers' requirement that patients do not wait excessively long for their treatment. This culminated in the NHS Executive issuing waiting time standards (guidance rather than a guarantee) commencing in April 1995. One possible effect of too much attention being paid to the least urgent, longest waiting patients is that the more urgent cases have to wait longer. To see if there was any evidence that this was starting to happen, the frequency distribution in 1992 of the time spent waiting for CABG after undergoing angiography was compared with 1994 (fig 23). There is no obvious change in the distribution of waiting times. Given that the Patient's Charter standards only started in April 1995, it may be too soon to observe any adverse affects on the waiting times of more urgent patients.

\section{COMMISSIONING}

Evolution of contracting

When the reforms were introduced in 1991, three regions (South East Thames, North Western, and Greater Glasgow) maintained the status quo as regards responsibility for purchasing the services (table 16). Contracts were paid centrally (by the Regional Health Authorities or the Scottish Office) by either top-slicing funds from district allocations or charging the district according to their level of use. East Anglian devolved the responsibility of purchasing to districts from the outset. After the initial maintenance of a steady state, the other regions also began to relinquish their control over the market and devolve the responsibility of contracting to either district purchasing consortia or individual districts. At the same time, the proportion of the population served by fund holding general practices increased, with the effect that the responsibility for purchasing CABG and PTCA increasingly shifted from purchasing authorities to the patient's own GP.

Meanwhile, in England the Department of Health introduced a new weighted capitation formula in 1991 to fund regions and it was recommended that they in turn should use it to allocate resources to district purchasing authorities. Each region slowly phased in the use of this formula to fund districts so that its use had become established in all regions by 1994/95. The new formula, based on capitation adjusted for age and a measure of need, caused a redistribution of resources, creating per capita losing and per capita gaining districts.

As the purchasing function developed with the advent of better information on treatment prices and activity, districts and district con-
Figure 22 Mean waiting times (days) for PTCA $1992 / 93$ and 1994/95, overall and by hospital (excluding 10\% longest waits).

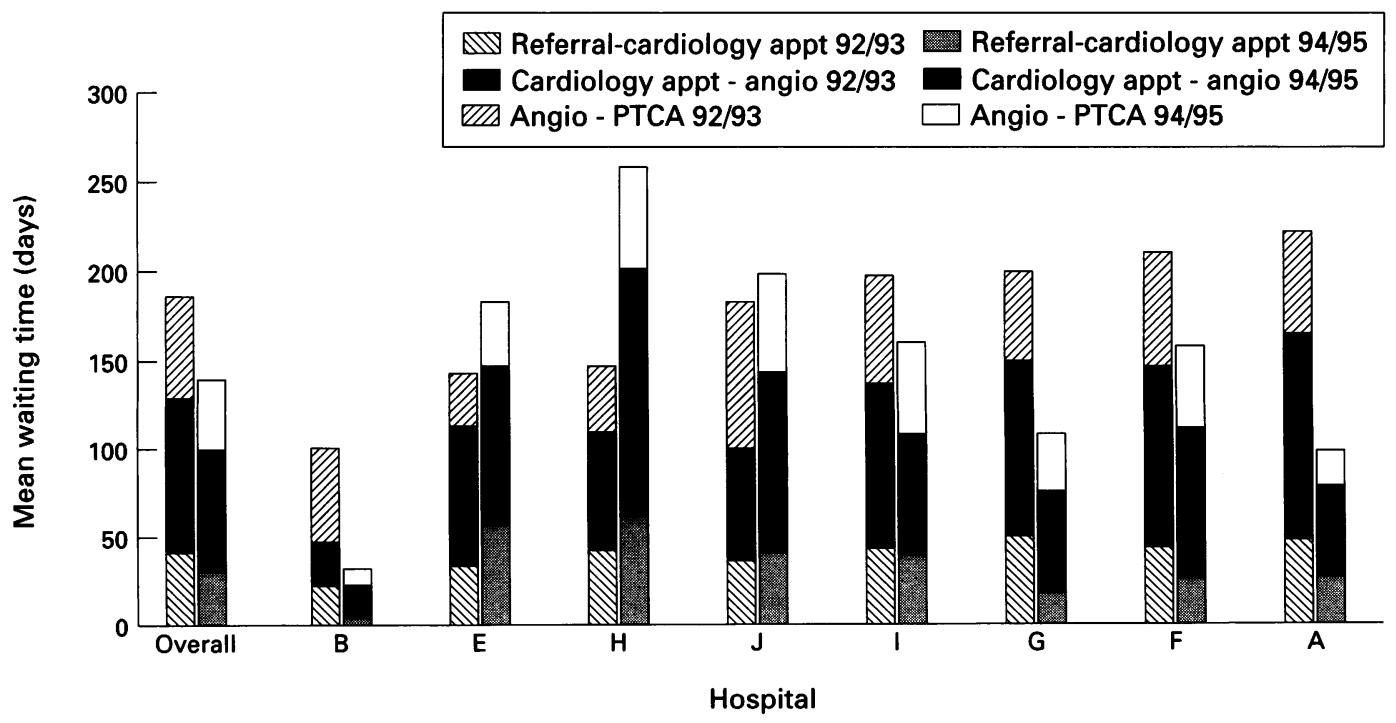




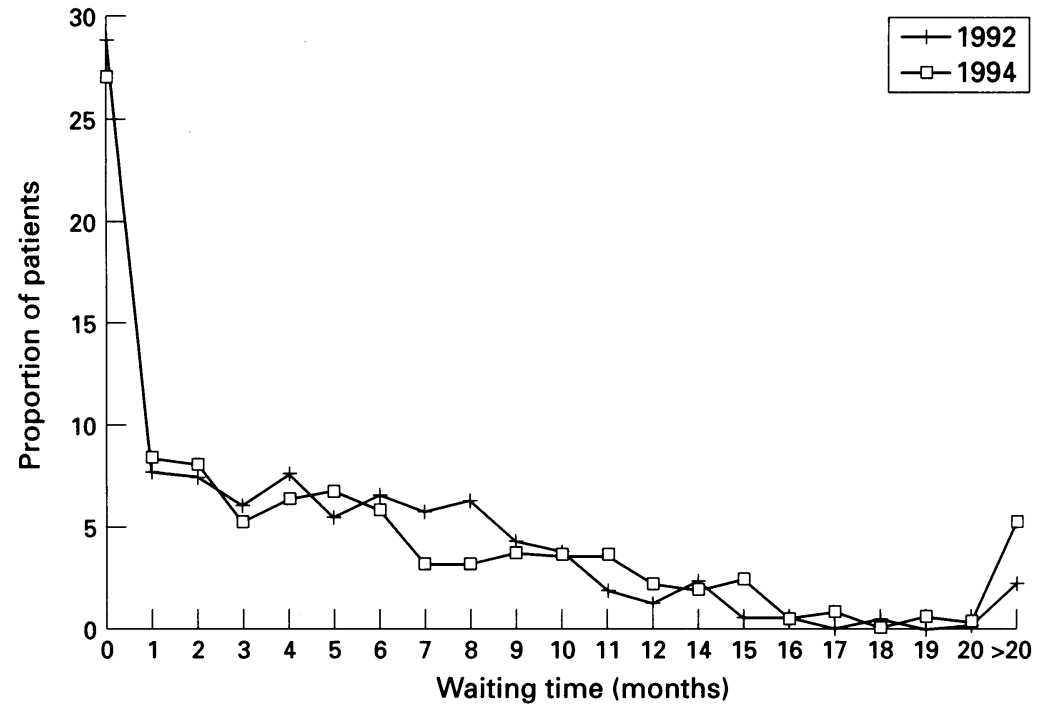

Figure 23 Frequency distribution of waiting times for CABG in 1992 and 1994.

sortia moved away from block contracts (table 17). Block contracts-where the purchaser pays the provider a fixed sum for access to a defined range of services to meet the demand from the purchaser's resident population-do not allow purchasers to increase the efficiency of resource use and place providers in a situation of uncertainty regarding their workload. Purchasers moved either to more sophisticated block contracts, where they set a target for the level of activity to be carried out based on projections of activity and treatment costs, or to cost and volume contracts, which are more precise as a fixed price is set for a specified target volume of treatment and then further activity is purchased at an agreed marginal cost up to a volume ceiling.

The length of contracts also changed. Initially, most contracts were for one year, at the end of which the need for the service was reviewed and the contract changed if required. North Western, however, chose to purchase services on a three year rolling contract so as to protect the service in the initial stages of the reforms. By 1994, hospitals were considering even longer contracts to enable them to carry out service developments. A seven year commitment from purchasers had been negotiated in East Anglian but was unlikely to be translated into a seven year contract due to a reluctance by purchasers to commit themselves to any one provider for so long. So despite intentions, contracts in all four regions in 1995/96 were still only for one year.

\section{Nature of the market}

When contracting was devolved to districts and district consortia from regions, providers were placed in the position of having to compete for contracts. Purchasers-both district health authorities and fundholding GPs started to question the configuration of services and the traditional choice of providers.

Purchasers initially contracted at historical levels of activity with providers with whom they had established links. As contracting developed, however, a spectrum of approaches to purchasing emerged. As regards volume, some purchasers said that they recognised cardiac surgery as a priority and sought to increase the level of activity so as to meet The health of the nation targets. In contrast, others continued to base contracts on historical trends in utilisation. As regards patient flows, the majority of purchasers did not change their referral patterns radically. Those that did were influenced by price rather than claims of improved quality. Some purchasers reduced the number of providers with whom they contracted, though this was mainly the result of central planning initiatives such as the Tomlinson Inquiry in London, rather than market forces. Clinicians played an influential

Table 16 Key features of commissioning in the four study regions from 1991/92 to 1995/96

\begin{tabular}{|c|c|c|c|c|c|c|}
\hline & & $1991 / 92$ & $1992 / 93$ & $1993 / 94$ & $1994 / 95$ & $1995 / 96$ \\
\hline $\begin{array}{l}\text { Responsibility } \\
\text { SE Thames } \\
\text { N Western } \\
\text { E Anglian } \\
\text { G Glasgow }\end{array}$ & $\begin{array}{l}\text { erchasing } \\
\text { CABG } \\
\text { PTCA }\end{array}$ & $\begin{array}{l}\text { Type } 1 \\
\text { Type } 2 \\
\text { Type } 4 \\
\text { N/A } \\
\text { N/A }\end{array}$ & $\begin{array}{l}\text { Type } 3 \\
\text { Type } 2 \\
\text { Type } 4 \\
\text { Type } 1 \\
\text { Type } 4\end{array}$ & $\begin{array}{l}\text { Type } 3 \\
\text { Type } 2 \\
\text { Type } 4 \\
\text { Type } 1 \\
\text { Type } 4\end{array}$ & $\begin{array}{l}\text { Type } 3 \\
\text { Type } 4 \\
\text { Type } 4 \\
\text { Type } 1 \\
\text { Type } 4\end{array}$ & $\begin{array}{l}\text { Type } 3 \\
\text { Type } 4 \\
\text { Type } 4 \\
\text { Type } 3 \\
\text { Type } 4\end{array}$ \\
\hline $\begin{array}{l}\text { Resource allo } \\
\text { SE Thames } \\
\text { N Western } \\
\text { E Anglian } \\
\text { G Glasgow }\end{array}$ & $\begin{array}{l}\text { CABG } \\
\text { PTCA }\end{array}$ & $\begin{array}{l}\text { Steady state } \\
\text { Steady state } \\
\text { Steady state } \\
\text { Steady state } \\
\text { Steady state }\end{array}$ & $\begin{array}{l}\text { Weighted capitation } \\
\text { Steady state } \\
\text { Weighted capitation } \\
\text { Steady state } \\
\text { Steady state }\end{array}$ & $\begin{array}{l}\text { Weighted capitation } \\
\text { Steady state } \\
\text { Weighted capitation } \\
\text { Steady state } \\
\text { Steady state }\end{array}$ & $\begin{array}{l}\text { Weighted capitation } \\
\text { Weighted capitation } \\
\text { Weighted capitation } \\
\text { Steady state } \\
\text { Steady state }\end{array}$ & $\begin{array}{l}\text { Weighted capitation } \\
\text { Weighted capitation } \\
\text { Weighted capitation } \\
\text { Steady state } \\
\text { Steady state }\end{array}$ \\
\hline $\begin{array}{l}\text { Type of princ } \\
\text { SE Thames } \\
\text { N Western } \\
\text { E Anglian } \\
\text { G Glasgow }\end{array}$ & $\begin{array}{l}\text { CABG } \\
\text { PTCA }\end{array}$ & $\begin{array}{l}\text { Block } \\
\text { Block } \\
\text { Cost and volume } \\
\text { N/A } \\
\text { N/A }\end{array}$ & $\begin{array}{l}\text { Block } \\
\text { Block } \\
\text { Cost and volume } \\
\text { Cost and volume } \\
\text { Block }\end{array}$ & $\begin{array}{l}\text { Sophisticated block } \\
\text { Block } \\
\text { Cost and volume } \\
\text { Cost and volume } \\
\text { Block }\end{array}$ & $\begin{array}{l}\text { Sophisticated block } \\
\text { Sophisticated block } \\
\text { Cost and volume } \\
\text { Cost and volume } \\
\text { Block }\end{array}$ & $\begin{array}{l}\text { Sophisticated block } \\
\text { Cost and volume } \\
\text { Cost and volume } \\
\text { Cost and volume } \\
\text { Block }\end{array}$ \\
\hline $\begin{array}{l}\text { Length of con } \\
\text { SE Thames } \\
\text { N Western } \\
\text { E Anglian } \\
\text { G Glasgow }\end{array}$ & $\begin{array}{l}\text { CABG } \\
\text { PTCA }\end{array}$ & $\begin{array}{l}12 \text { months } \\
3 \text { year } \\
12 \text { months } \\
\text { N/A } \\
\text { N/A }\end{array}$ & $\begin{array}{l}12 \text { months } \\
12 \text { months } \\
12 \text { months } \\
12 \text { months }\end{array}$ & $\begin{array}{l}12 \text { months } \\
12 \text { months } \\
6 \text { months } \\
12 \text { months }\end{array}$ & $\begin{array}{l}12 \text { months } \\
12 \text { months } \\
12 \text { months } \\
12 \text { months } \\
12 \text { months }\end{array}$ & $\begin{array}{l}12 \text { months } \\
12 \text { months } \\
12 \text { months } \\
12 \text { months } \\
12 \text { months }\end{array}$ \\
\hline
\end{tabular}

Type 1: Regional purchasing in which region established contracts with local providers and top-sliced funds for these services.

Type 2: Regional purchasing in which region contracted with providers and charged districts according to their level of use.

Type 3: District purchasing consortia in which the responsibility for purchasing these services has been devolved to districts who have formed purchasing consortia. Type 4: District purchasing in which the responsibility for purchasing was taken on by individual districts.

N/A: Not applicable.

( ${ }^{\star A n}$ agreement was sought from all main purchasers for a seven year commitment although contracts would still be issued on a one year basis). 
Table 17 Types of contracts

\begin{tabular}{ll}
\hline Type & Definition \\
\hline Simple block & $\begin{array}{l}\text { Purchasers pay the provider a fixed sum for access to a defined range } \\
\text { of services or facilities. Such contracts may include some form of } \\
\text { indicative workload agreement or fixed volume. }\end{array}$ \\
Sophisticated block & $\begin{array}{l}\text { Purchasers pay providers a fixed contract sum for access to a defined } \\
\text { range of services or facilities. Indicative patient activity targets or } \\
\text { thresholds with efloors" and ceilings" are included in such } \\
\text { contracts as well as agreed mechanisms if targets are exceeded. Some } \\
\text { elements of case mix may be included. } \\
\text { This contract specifies outputs in terms of patient treatment rather } \\
\text { than inputs in terms of services or facilities available. Purchasers do } \\
\text { not purchase fixed volumes but will develop contracts with a fixed } \\
\text { price being paid up to a certain volume of treatment and a price per } \\
\text { case being paid above it, up to a volume ceiling. } \\
\text { The hospital agrees to provide a range of specified treatments in line } \\
\text { with a given contract price. }\end{array}$ \\
\hline Cost per case &
\end{tabular}

Source: NHS Executive, Purchasing Unit (1994).

role in how these services were commissioned and were present at most purchaser/provider meetings.

In general the contractual relations between, on the one hand, purchasers and their main providers and, on the other hand, between providers and their main purchasers were stable (table 18). In South East Thames the providers felt that the relationship was open because information about activity, costs, and quality was shared freely with purchasers. This view of stability and openness was not held, however, by their purchasers who were actually in the process of altering their referral patterns and switching contracts. In contrast, the views of purchasers and providers appeared to be concordant in the other three regions, in part because of the lack of alternative local providers.

In English regions fund holding GPs were responsible for paying for these procedures, but not in Scotland. Fund holding GPs do not have to pay for coronary angiography. This will change, however, with the introduction of total purchasing under which GPs will be responsible for meeting the costs of all services consumed by their patients. What effect this will have on coronary revascularisation rates is unclear at present but would need to be monitored.

Despite the contractual relationship between purchasers and providers being predominantly stable, all providers felt that they had to compete for contracts (table 18). This competitive environment arose as a result of providers having to maintain their contracts with their main purchasers, compete for contracts from more distant districts, and compete for patients from fund holding GPs who were controlling an ever increasing proportion of the market.
Providers were divided in their views as to the fairness of competition. In South East Thames and North Western some felt-for several reasons-that competition through competitive tendering was unfair. First, they argued that purchasers assessed tenders with regard to the price but not the quality of the service provided. Second, this concern was compounded by the feeling that prices were not considered representative of a provider's efficiency because of the different methods used to determine costs. Third, it was felt that tenders were more likely to be offered to inefficient providers who, charging their main local purchasers full cost and retaining excess capacity, could then charge other more distant purchasers at marginal cost to attract additional tenders. And finally, providers also felt that in the early years the special health authorities (in London) had an unfair advantage since they had been allowed to charge lower prices due to subsidies received for research and teaching.

\section{Concerns about commissioning in 1991/92}

In the first year of the reforms, when most regions retained control over purchasing these services and before the traditional means of allocating resources to districts gave way to weighted capitation, purchasers and providers struggled to deal with the problems the new contracting system imposed (table 19). They faced seven new challenges.

(1) Both purchasers and providers had problems regarding the type of contract to use. Block contracts were a high risk for providers and many found that their actual level of activity exceeded the anticipated level, leading to a financial loss. In contrast, cost and volume contracts sometimes caused waiting lists to grow because as the number of emergencies rose, the number of elective cases that could be undertaken within a fixed volume contract fell. This was avoided if purchasers agreed to fund more cases at marginal cost. While block contracts gave no guarantee to purchasers as to the volume and type of work that would be carried out, cost and volume contracts were difficult to define due to the inability of providers to price their services according to case mix.

(2) Lack of information on which to base contracts was a limiting factor for both parties. Providers were concerned about the expense they faced in collecting data on the cost and quality of services. Purchasers, unable to make

Table 18 Key features of the relationship between purchasers and providers and providers responses to questions regarding the competitive environment in 1993/94

\begin{tabular}{|c|c|c|c|c|}
\hline & $\begin{array}{l}\text { Providers: } \\
\text { "What is your relationship } \\
\text { with your main purchasers?" }\end{array}$ & $\begin{array}{l}\text { Purchasers: } \\
\text { "What is your relationship } \\
\text { with your main providers?" }\end{array}$ & $\begin{array}{l}\text { Providers: } \\
\text { "Do you compete for } \\
\text { contracts?" }\end{array}$ & $\begin{array}{l}\text { Providers: } \\
\text { "Is the basis of competition } \\
\text { fair?" }\end{array}$ \\
\hline SE Thames & $\begin{array}{l}\text { Stable open contractual } \\
\text { relationship }\end{array}$ & $\begin{array}{l}\text { Short term buying and } \\
\text { selling arrangements }\end{array}$ & Yes & $\begin{array}{l}\text { No, tendering process is } \\
\text { unfair and Special Health } \\
\text { Authorities have an unfair } \\
\text { advantage }\end{array}$ \\
\hline & \multirow{3}{*}{$\begin{array}{l}\text { Stable contractual } \\
\text { relationship } \\
\text { Stable long term } \\
\text { contractual relationship } \\
\text { Stable contractual } \\
\text { relationship }\end{array}$} & \multirow{3}{*}{$\begin{array}{l}\text { Stable contractual } \\
\text { relationship } \\
\text { Stable long term } \\
\text { contractual relationship } \\
\text { Stable contractural } \\
\text { relationship }\end{array}$} & Yes & $\begin{array}{l}\text { No, tendering process and } \\
\text { regulation by region is unfair }\end{array}$ \\
\hline E Anglian & & & Yes & Yes \\
\hline G Glasgow & & & Yes & Yes \\
\hline
\end{tabular}


Table 19 Problems experienced by purchasers and providers in 1991/92, 1993/94 and 1994/95

\begin{tabular}{|c|c|c|c|}
\hline & Problems experienced in 1991/92 & New problems experienced in $1993 / 94$ & New problems experienced in $1994 / 95$ \\
\hline Providers & $\begin{array}{l}\text { (1) Type of contract } \\
\text { (2) Lack of routine information } \\
\text { (3) Appropriate organisational level for purchasing } \\
\text { (4) Uncertainty about demand } \\
\text { (5) Achieving equality between purchasers } \\
\text { (6) Lack of fair competition }\end{array}$ & $\begin{array}{l}\text { (1) Inability to carry out service developments } \\
\text { (2) Problems related to fundholding GPs } \\
\text { (3) Problems related to waiting times }\end{array}$ & $\begin{array}{l}\text { (1) New technologies eg, stents } \\
\text { (2) Staff recruitment problem } \\
\text { (3) Shortage of investment funds } \\
\text { (4) Uncertainty brought about by the general } \\
\text { election }\end{array}$ \\
\hline Purchasers & $\begin{array}{l}\text { (1) Type of contract } \\
\text { (2) Lack of routine information } \\
\text { (3) Appropriate organisational level for purchasing } \\
\text { (4) Weighted capitation } \\
\text { (5) Setting specialties against each other } \\
\text { (6) Conflict with The health of the nation }\end{array}$ & $\begin{array}{l}\text { (1) Managing demand } \\
\text { (2) Difficulties with price comparability } \\
\text { (3) Lack of information on patient outcomes }\end{array}$ & (1) New technologies \\
\hline
\end{tabular}

comparisons between providers on the basis of quality due to a lack of uniform indicators, were having to base their choice on price alone. Even when a purchaser had placed a contract, monitoring the service was again hampered by lack of data.

(3) The appropriate organisational level for purchasing was a concern both for providers and purchasers. Providers found it easier to negotiate contracts which covered more than one district, as this avoided the time and expense of negotiating lots of small volume contracts with their inevitable risks. On the purchasing side there was a conflict between regions and districts about who should be responsible for purchasing. The former argued that districts did not have the necessary skills and that if these services were purchased on a regional basis equality of access could be ensured. However, the districts argued that they were in a better position both to assess the needs of their resident population and to choose between competing demands.

(4) Providers faced difficulties in managing demand for their services as they were uncertain about the actual number of patients that would be referred to them. This in turn both reflected the difficulties purchasers faced in coming to terms with their new functionwhich sometimes led to contracts being agreed after the financial year had begun-and the impact of the introduction of weighted capitation. The new funding formula meant that some providers situated in per capita losing areas suffered a reduction in income, which in turn caused problems for their purchasers who as a result had to cover a higher proportion of the provider's fixed costs.

(5) Providers became aware of their inability to provide a fair and equitable service to their various purchasers. They found the clinical priority of patients was being distorted by the amount of resources purchasers were allocating for these services. Quite often providers completed a contract for a purchaser but there were still patients waiting urgent treatment. Meanwhile contracts with other purchasers were continuing in which patients in less need of urgent attention were being treated. Providers were frustrated with their powerlessness to treat patients according to clinical need.

(6) Some providers considered the basis of competition unfair. Well established providers were thought to be able to compete more effectively than those who were trying to develop their service. Also some providers felt there was too much central control over the market which tended to favour certain providers over others.

(7) Purchasers found they were coming up against several conflicts. In setting priorities for health care, they felt that involving clinicians from the provider units in discussions about how to chose between competing needs for health care would result in setting specialties against each other. Purchasers also found that contracting could be in direct conflict with The health of the nation policies as contracting rewarded purchasers who achieved maximum efficiency gains as measured by the efficiency index. As the definition of efficiency was based on maximising patient activity from the resources available, it followed that purchasers achieved higher efficiency gains by increasing hospital activity rather than by moving resources from treatment to prevention, a strategy that was believed to be more likely to meet the goals set in The health of the nation.

Concerns about commissioning in 1993/94

Two years later, when contracting had become better established, some of the early problems had resolved, some remained and some new ones had emerged (table 19). Handling the logistics of contracting was no longer seen to be as serious a problem for purchasers and providers because of the skills that had been developed over the preceding three years. Routine data on costs and activities of cardiac services were being collected so that more sophisticated contracts could be used. This, to a large extent, had taken much of the uncertainty out of contracting.

Providers were still concerned about how to manage demand for cardiac services. They were experiencing problems with contractual volumes being exceeded because of an increase in the number of emergencies and an overall increase in referrals. They were also still concerned about their inability to treat patients solely according to clinical need.

Purchasers had also become increasingly concerned about the dramatic increase in demand for CABG and PTCA by their resident population over the previous few years. One reason for the increase was that cardiologists from specialist centres had set up more clinics in district general hospitals, particularly in districts with traditionally low referral rates, and were conducting outpatient sessions in fund holding general practices. Another rea- 
son was that diagnostic facilities, including angiography, had been developed in some district general hospitals. The resulting increase in demand from traditionally low referring districts had not been offset by a decrease in districts with historically high referral rates. Purchasers who were losing resources under weighted capitation were finding it difficult to reduce their commitment to these services in view of increasing demand. As a result, greater pressure was put on reducing expenditure on other services.

Lack of fair competition was still causing a problem for providers, though the nature of their concern had changed to that of pricing. Many felt that they were put at a competitive disadvantage as a result of being efficient and pricing their services at true average cost. Other providers with much lower prices were felt to be distorting the market in a variety of ways including using cardiac services as a "loss leader" to attract business for other services, subsidising the service through monies received for research functions, cross subsidising between services (despite having been outlawed by the NHS Management Executive), or charging local purchasers the full cost while allowing other purchasers to use their services at marginal cost.

Lack of data on the quality of the service remained a problem for purchasers who were continuing to select providers on the basis of price. However, they found it was almost impossible to make meaningful comparisons of prices because providers did not all use the same cost accounting systems, apportionment rules, and methods of product specification. They felt that price alone could not be used as an indication of efficiency unless all providers used the same method of pricing and achieved the same outcome.

Purchasers were also still finding that contracting sometimes conflicted with the objectives of The health of the nation. Purchasers argued that the more of their patients that were treated, the more credibility they received because treating patients was easily quantifiable while promoting health was not.

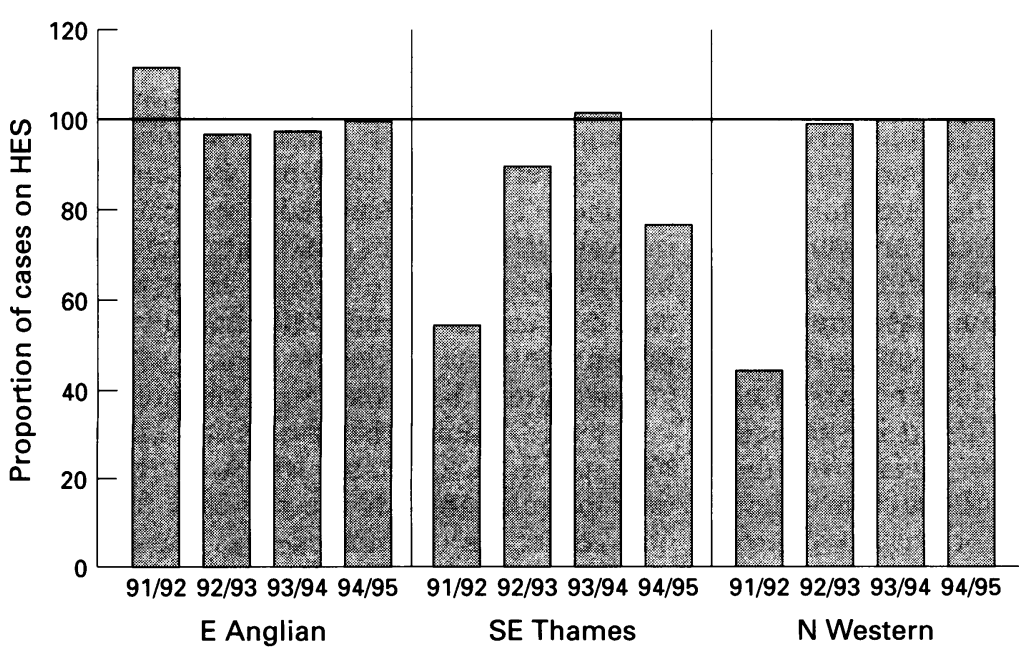

Figure 24 Completeness of Hospital Episode System data for CABG in three study regions.
Several new problems had emerged for providers. First, providers had become increasingly concerned about the future development of their services. Demand for the service had risen, with no increase in the amount of resources available. Providers therefore found that their ability to carry out service developments was limited. Second, growth in the number of fund holding GPs added to the existing equity problems. Although providers generally did not have an explicit policy of giving the patients of fund holding GPs a better service, several found that as a result of market pressures and the need to maintain their share of the ever increasing market controlled by fund holding GPs, they had to provide a quicker, cheaper, and sometimes better quality service than that provided for district purchasers. Third, although target waiting times were welcomed by providers, many found that they were either having to distort clinical priorities in order to achieve them or refer nonurgent cases back to their GPs rather than put them on a waiting list. This problem had arisen because many purchasers were still buying services on a historical basis and were not basing their decisions on the need to achieve the 12 month inpatient waiting time target.

Concerns about commissioning in 1994/95

The predominant concern for purchasers continued to be how to manage the increase in demand for coronary revascularisation services. This problem had become exacerbated by the introduction of a new technology, intracoronary stents, which placed additional financial pressure on their budgets. Providers concerns were more wide ranging. They included problems arising from: having to meet waiting time targets; the increasing number of fund holding GPs; the introduction of new technologies; difficulties recruiting staff; a lack of investment for future development; and uncertainty about future government policies.

Providers were still concerned about how to meet national waiting time targets for patients from those districts who had to reduce their expenditure on coronary revascularisation services because of losing resources through weighted capitation. Furthermore, some districts had set their own local waiting time standards, ranging from three to nine months, which some providers were finding it difficult to meet. Fund holding GPs continued to create problems as they purchased services on a cost-per-case basis. As this non-contracted activity was sometimes large in relation to a hospital's contracted activity, it created uncertainty and made it difficult for hospitals to manage their workload efficiently through the year. Furthermore, in one region, concern was raised over the formula used to determine GPs' budgets for these services.

The introduction of stents had led to changes in clinical practice and increased the costs of carrying out PTCA. There was uncertainty as to the effectiveness and cost-effectiveness of stents and the criteria for their appropriate use. 


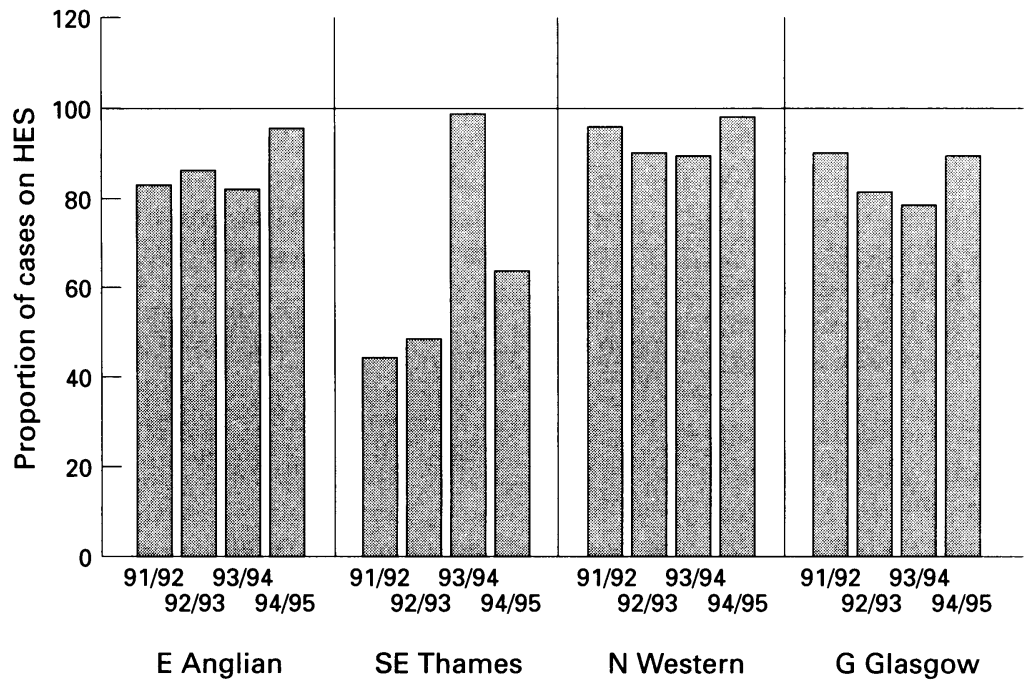

Figure 25 Completeness of Hospital Episode System (HES) data (SMRI system in Scotland) for PTCA in four study regions.

Table 20 Proportion of cases (NHS and private) treated in intraregional NHS hospitals reported in Hospital Episode System (HES)* data

\begin{tabular}{|c|c|c|c|c|c|}
\hline \multirow[b]{2}{*}{ Region } & & \multicolumn{2}{|l|}{$C A B G$} & \multicolumn{2}{|l|}{$P T C A$} \\
\hline & & Region & District range & Region & District range \\
\hline \multirow[t]{6}{*}{ E Anglian } & $1987 / 88$ & 81 & 71 to 105 & 33 & - \\
\hline & $1989 / 90$ & 100 & 88 to 124 & 116 & 73 to 181 \\
\hline & $1991 / 92$ & 111 & 104 to 125 & 83 & 62 to 103 \\
\hline & $1992 / 93$ & 96 & 82 to 105 & 86 & 75 to 100 \\
\hline & $1993 / 94 \$$ & 97 & 92 to 101 & 82 & 74 to 90 \\
\hline & $1994 / 95$ & 99 & 87 to 104 & 95 & 75 to 100 \\
\hline \multirow[t]{4}{*}{ N Western } & $1991 / 92$ & 43 & 23 to 70 & 95 & 33 to 107 \\
\hline & $1992 / 93$ & 99 & 82 to 118 & 90 & 77 to 111 \\
\hline & $1993 / 94$ & 100 & 83 to 111 & 89 & 71 to 117 \\
\hline & $1994 / 95$ & 100 & 69 to 122 & 97 & 38 to 145 \\
\hline \multirow[t]{4}{*}{ SE Thames $\$$} & $1991 / 92$ & 53 & 8 to 96 & 44 & 18 to 57 \\
\hline & $1992 / 93$ & 89 & 73 to 123 & 48 & 31 to 87 \\
\hline & $1993 / 94 \$$ & 101 & 87 to 107 & 99 & 87 to 104 \\
\hline & $1994 / 95$ & 76 & 27 to 98 & 63 & 17 to 94 \\
\hline \multirow[t]{4}{*}{ G Glasgowi } & $1991 / 92$ & - & - & 90 & 85 to 91 \\
\hline & $1992 / 93$ & - & - & 81 & 52 to 112 \\
\hline & $1993 / 94$ & - & - & 78 & 64 to 112 \\
\hline & $1994 / 95$ & - & - & 89 & 77 to 94 \\
\hline
\end{tabular}

^Data from SMR1 system in Scotland.

$\uparrow$ Excludes private cases.

$\$$ Number of districts reduced as a result of mergers.

In some regions providers were having difficulties expanding capacity to meet the increase in demand due to problems of recruiting staff, especially anaesthetists. In addition providers were concerned about the future development of their services, given the lack of long term investment by purchasers. One of the reasons given for the lack of planning for the future was the uncertainty around any potential change in government policy following a change of political party in office.

\section{Future developments}

There are several developments in the field of coronary revascularisation services which are likely to have an impact on the commissioning of these services in the future. These include the introduction of open access exercise testing, the development of invasive diagnostic facilities in district general hospitals, the demise of the Regional Health Authority, the introduction of total fund holding, and the separation of funding for research and training from that of service provision.

The introduction of open access exercise testing has been supported by some purchasers and providers and opposed by others.
It has been or soon will be introduced in each region. Although access to diagnostic tests would be improved, it is felt that it would be more cost-effective for patients to be assessed only by cardiologists and that GPs should not refer patients for diagnostic tests unless there was a strict protocol in place. The development of invasive diagnostic facilities in district general hospitals has already occurred in three regions. In the fourth region, district general hospitals are assessing the feasibility of such a development.

The influence of the regional health authorities on these services is decreasing. They already have little influence in East Anglian and South East Thames but have continued to have an active role in North Western. Providers were in agreement that they would prefer more central guidance than currently exists and felt that a national target for CABGs and PTCAs should be set. However, they stressed the need for local assessment as any national target would not take into account regional variations in need. Generally, purchasers preferred to contract on the basis of local need rather than have central guidance on the target numbers of CABG and PTCA to be purchased. It was felt that central guidance might conflict with local need.

The majority of providers felt that unless fund holding GPs formed consortia or multifunds, the introduction of total purchasing would be extremely destabilising. While fund holding GPs are currently not paying for angiography, they will do so when they are total purchasers. Providers felt this could have a destabilising effect on the service given the large number of small contracts the provider would have to deal with. Providers felt that the administrative costs of contracting would escalate. The main concerns related to the uncertainty created by GPs purchasing on a cost-per-case basis and the problems created by GPs moving their patients at short notice from one hospital to another, with shorter angiography and coronary revascularisation waiting times. Both problems would place providers in a situation where they were unable to determine workload and therefore were unable to manage their resources efficiently throughout the year. Providers were also concerned about the indirect effects of total purchasing. Given that GPs would be responsible for purchasing all the services their patients needed, emergency demands might usurp elective needs and lead to a reduction in coronary revascularisations.

Finally, both the Task Force on funding research in the NHS and the introduction of competition have affected research and teaching, with the result that providers feel there are less resources and less time for these activities. Staff recruitment problems in some areas, especially in anaesthetics, have been attributed to these changes.

\section{Future monitoring arrangements}

To determine the optimum method for future monitoring arrangements, the completeness of routine NHS data was assessed. Comparison 
of the numbers of CABG and PTCA cases reported by the Hospital Episode System (HES) with the numbers derived from provider units shows some serious shortfalls during the early years of the study (figs 24 and 25). By $1994 / 95$ data at the regional level was complete for CABG (except for South East Thames). Though it had improved for PTCA, there was still a shortfall of $37 \%$ in South East Thames, $11 \%$ in Greater Glasgow, and 3-5\% in East Anglian and North Western.

Even those regions with fairly complete data recording conceal significant shortfalls for some of their districts (table 20). In 1994/95, the data for some districts were as low as $27 \%$ and as high as $122 \%$ for CABG, and for PTCA the range was $17 \%$ to $145 \%$.

\section{Summary of the results}

The aims of this study were to describe: the availability of and access to CABG and PTCA purchased by the NHS; the variation that exists within the United Kingdom; and the impact of the NHS reforms introduced in April 1991. To achieve these aims five objectives were established each of which will be addressed in turn.

Objective 1: To describe changes in the availability of CABG and PTCA in a representative sample of regions in terms of location, staff and facilities between 1987/88 and 1994/95 .

- Accurate measurement of the number of medical and surgical staff and beds available to carry out CABG and PTCA is difficult.

- There has been little change in the availability of consultants in cardiology in specialist centres between 1987 and 1995. The number of non-consultant cardiologists has risen significantly in North Western and Greater Glasgow. Overall, the number of cardiologists trained to perform PTCA has increased, as has the number of cardiologists in district hospitals. Bed provision has increased recently in South East Thames and Greater Glasgow.

- The availability of medical staff in specialist centres varies between regions-North Western and South East Thames have considerably higher staffing levels than East Anglian region.

- The availability of cardiology beds shows less inter-regional variation, though South East Thames had more than the other regions.

- The availability of consultant surgeons showed little or no change between 1987 and 1995 in South East Thames and North Western but more than doubled in Greater Glasgow and East Anglian. The provision of non-consultant surgical staff has increased by $40-90 \%$.

- Consultant surgical staffing levels in East Anglian region, which had been about half that of the other three regions up until 1992-93, had increased to a similar level by 1994/95.
- The ratio of consultants to non-consultants in cardiac surgery was $1: 2$ in all regions apart from East Anglian where it was 1:1.

- The availability of surgical beds is similar in all regions despite the recent rise in South East Thames and the fall in the number of beds in North Western in 1992/93.

Objective 2: To compare the age and sex standardised population rates for CABG and PTCA between regions, districts, and boards included in the sample and consider how any differences have changed between 1987/88 and 1994/95.

- National data sources (NHS, professional associations, pressure groups, private insurers) lack sufficient detail and accuracy to monitor access and availability.

- Assessment of NHS purchased services requires inclusion of cross boundary flows and provision by private hospitals.

- Hospital data on individual patients have improved since 1987/88.

- Some private hospitals in London would not or could not provide data needed for the study.

- The NHS rate of use of both procedures has increased steadily since $1987 / 88$. The 1991 NHS reforms have had no obvious impact on the growth in the use of coronary revascularisation.

- Between 1987/88 and 1994/95, regional rates of CABG rose by $175 \%$ in Greater Glasgow, $185 \%$ in South East Thames, $91 \%$ in North Western, and 286\% in East Anglian region. Rates of PTCA rose by $219 \%$ in Greater Glasgow, 239\% in North Western, 523\% in South East Thames, and $1963 \%$ in East Anglian region (though this was from a very low initial level).

- In 1994/95, only two of the 45 districts and boards studied had CABG rates of less than 300 per million total population, down from 17 districts in 1992/93.

- The extent of inter-regional cross boundary flow of NHS cases has fallen over time and varies between regions from none to $5 \%$ for CABG and from none to $16 \%$ for PTCA. The additional contribution of privately funded cases in 1994/95 varied between regions from $14-23 \%$ for $C A B G$ and $7-30 \%$ for PTCA. The PTCA data omit South East Thames in which the private contribution may have been greater than $30 \%$.

- Regional rates for NHS funded cases varied 1.3-fold for CABG and threefold for PTCA in $1994 / 95$, considerably less than 1991/92.

- In 1994/95 the regional NHS rate for PTCA was $30-40 \%$ of the CABG rate except in South East Thames where the rates were similar.

- In 1994/95 NHS CABG rates varied 3.6fold and PTCA rates varied 18-fold between the 42 districts and boards included in the study.

- Interdistrict variation in NHS rates has decreased over time. CABG rates show 
low variation in East Anglian and North Western, and moderate variation in South East Thames. Variation in Greater Glasgow has traditionally been low though was unusually high in 1994/95.

- Interdistrict variation in NHS PTCA rates remains high in East Anglian and South East Thames and moderate in North Western, reflecting its more recent introduction than CABG.

- The amount of interdistrict variation when both procedures are considered was low in East Anglian and North Western, moderate in Greater Glasgow, and high in South East Thames. The reduction in variation over time may be a consequence of the reforms, the continuing spread of cardiology services to district general hospitals, or the inevitable consequence of the diffusion of two relatively new procedures.

- Revascularisation rates were higher in districts with least need (as measured by SMR) in 1991/92 and this has persisted over the following three years. While rates were higher in more socially deprived districts in 1991/92 (possibly due to the location of tertiary centres in inner city areas), this relation had disappeared by $1994 / 95$, thus providing further evidence that rates of revascularisation are not linked to the apparent level of need.

Objective 3: To describe the waiting time (a) from GP referral to outpatients, (b) from outpatients to angiography, and (c) from angiography to CABG or PTCA; how it varies between NHS provider units within the four regions; and how it has changed between 1992/93 and $1994 / 95$

- It is extremely difficult to get accurate data on component sections of waiting times collected in a standardised way from several hospitals. The results must therefore be interpreted cautiously.

- In 1994/95 CABG patients referred by their GP waited 39 days (interhospital range $=8$ to 67) to see a cardiologist, a further 58 days (range $=2$ to 125 ) for an angiogram, and 117 days (range $=65$ to 188) to undergo surgery. (These data exclude the $10 \%$ of patients with the longest times spent in these periods.)

- Overall waiting time for GP referred CABG patients varied significantly between hospitals from 113 to 298 days. The main contributor to the overall waiting time was the period between the angiogram and surgery.

- In 1994/95 PTCA patients referred by their GP waited 31 days (range $=5$ to 63 ) to see a cardiologist, a further 67 days (range $=$ 17 to 138) for an angiogram, and an additional 40 days (range $=9$ to 56 ) for angioplasty. (These data exclude the $10 \%$ of patients who spend the longest times in these periods.)

- Overall waiting time for GP referred PTCA patients varied significantly between hospitals from 32 to 257 days. The major contributor to the overall waiting time was waiting for an angiogram.
- The overall waiting time for CABG (214 days) was largely unchanged from 1992/93 (234 days). There was no significant change in the mean lengths of each of the three component waiting periods. The waiting time in some hospitals had, however, increased considerably while in others it had decreased.

- The overall waiting time for PTCA (138 days) was $25 \%$ shorter than in $1992 / 93$ (185 days). Reductions occurred in the mean lengths of each of the three component waiting periods. The waiting time in some hospitals had, however, increased considerably.

- There was no change in the distribution of the time spent waiting for CABG after angiography between 1992 and 1994 . Prioritisation of patients waiting over a year had not yet adversely affected the waiting time of more urgent patients.

Objective 4: To review past, current and future policies for funding and providing CABG and PTCA including the types of purchasing contracts being used.

- There has been a complex web of interconnected problems which, in general, caused more problems for purchasers than providers initially but which appear to be of increasing concern to providers.

- The purchasing function has developed considerably over the last four years and the contracting process has become more sophisticated. Regions have largely relinquished their control over the market for specialist services and devolved the responsibility to districts, district consortia, and fund holding GPs whose purchasing skills are still developing.

- There remain a lack of appropriate data on costs and quality on which to base contracts. Purchasers have dealt with this problem by creating sophisticated block contracts or cost and volume contracts, where they agree with the provider on a target level of activity to be carried out for a fixed sum.

- Purchasers find that the increasing demand for CABG and PTCA, in part brought about by initiatives set up by providers and in part by the introduction of new technologies, are putting an increasing burden on their limited budget.

- Providers have become increasingly concerned about commissioning. Concerns include: the increasing demand for their services with no concurrent increase in the resources available; the purchasers' use of tendering; a sense of unfair competition in the market place; inability to maintain clinical need as the basis of selecting patients; inability to recruit the staff they require; and considerable uncertainty, in part brought about by fundholding GPs. Some providers have attempted to secure longer term contracts but purchasers have bee reluctant to commit themselves for longer than one year.

- Despite guidance from the NHS 
Executive, some purchasers and providers are concerned that some of their rivals price procedures as loss leaders and offer different prices to different purchasers.

- There are several developments in the field of coronary revascularisation which are likely to have a considerable impact in the future. These include the introduction of open access exercise testing and intracoronary stents, the development of invasive diagnostic facilities in local district general hospitals, the demise of the regional health authority, the introduction of total fund holding, and the lack of resources for research and training. The absence of a strategic planning mechanism is of concern to providers.

- With a lack of nationally agreed risk categories for classifying patients, providers have use a variety of systems, making comparisons between providers almost impossible.

Objective 5: To determine the optimum method for future monitoring arrangements including the completeness of routine NHS data.

- While there has been some improvement over recent years, the HES and SMR1 system remain inaccurate sources of data for assessing district utilisation rates for CABG and PTCA.

This study was carried out for the Clinical Standards Advisory Group committee on access to and availability of specialised services. Members of its working group on coronary revascularisation were: Sir Terence English, Mr John Parker, Dr John Perrins, and Dr Gordon Pledger. We would like to thank them for their advice and the many people who helped us to compile this report by supplying data, agreeing to be interviewed, and providing written views. A list of those who assisted us appears in
Appendix 6 . In addition we would like to thank Mark Petticrew Appendix 6. In addition we would like to thank Mark
of the HSRU, LSHTM for help in analysing the data.

1 English TA, Bailey AR, Dark JF, et al. The UK cardiac surgical register, 1977-82. BMF 1984;289:1205-8.

2 King's Fund Consensus Development Conference Panel. Coronary artery bypass grafting. $B M \mp 1984 ; 289: 1527-9$.

3 Department of Health. Resource assumptions and planning guidelines. $\mathrm{HC}(87) 7,1987$.

4 Society of Thoracic and Cardiovascular Surgeons of Great Britain and Northern Ireland. United Kingdom Cardiac Surgical Register 1993/94, 12 March 1995.

5 Clinical Standards Advisory Group. Coronary artery bypass grafting and coronary angioplasty. Access to and availability of specialist services. Report of a CSAG Working Group. London: HMSO, 1993.

6 National Heart Foundation of Australia. Cardiac surgery 1992. Report No 30. August 1994.

7 Unger F. European survey on cardiac interventions in 1994. Ann European Acad Sci Arts 1995;12.

8 Working Party of the British Cardiac Society. Coronary angioplasty in the United Kingdom. Br Heart $\mathcal{F} 1991 ; 66$ : 325-31.

9 Hubner PJB. Cardiac interventional procedures in the United Kingdom during 1989. Br Heart $\mathcal{f}$ 1991;66: 469-71.

10 Hubner PJB. Cardiac interventional procedures in the United Kingdom in 1990. Br Heart $\mathcal{F} 1992 ; 68: 434-6$.

11 Joint Cardiology Committee of the RCP (London) and RCS (England). Provision of services for the diagnosis and treatment of heart disease. Br Heart 7 1992;67: and trea.m.

12 Wilson R, Allen P. Medical and dental staffing prospects in the NHS in England and Wales 1993. Health Trends 1994;26:70-9.

13 McPherson K, Wennberg JE, Hovind OB, Clifford P. Small-area variations in the use of common surgical procedures: an international comparison of New England, England and Norway. N Engl f Med 1982;307:1310-4.

14 Black NA, Langham S, Petticrew M. Coronary revascularisation: why do rates vary geographically in the UK? $₹$ sation: why do rates vary geographically in 
patients reported by Groves et al. They show, in any case, remarkable similarities in relation to the location of the block within the atrioventricular node. They all had a wide QRS which suggests a distal block within the bundle of His. Groves et al performed a pathological examination of the hearts of their patients and demonstrated a distal lesion of the bundle of His of the type of nodoventricular block instead of atrioventricular block. ${ }^{2}$ This is in accordance with the pathological findings of Ho et $a l^{3}$ and with the clinical data presented by FrohnMulder et $\mathrm{al}^{4}$ who noted that the QRS width was wider in a group of anti-Ro negative patients compared with a group of anti-Ro positive children.

Pathogenic mechanism of isolated congenital heart block has been related to immune mechanisms mediated by anti-Ro or anti-La antibodies. Immune mediated damage is usually located proximal to the bundle of His. Damage of the conduction system in anti-Ro negative patients seems to be located distal to the bundle of His. This may explain a lower ventricular rate which could explain the poor outcome of Groves et al's patients. Further serological and familial studies of anti-Ro negative patients may give insight into the mechanism of the disease.

$$
\text { LUIS G GUERETA }
$$
$M$ BURGUEROS F MORENO Cardiologia Infantil, Hospital La Paz,
Madrid, Spain

1 Groves AMM, Allan LD, Rosenthal E. Outcome of isolated congenital complete heart block diagnosed in utero. Heart 1996; 75:190-4

2 Lev M, Silverman J, Fitzmaurice FM, Paul MH, Cassels DE, Miller RA. Lack of con- nection between the atria and the more peripheral conduction system in congenital atrioventricular block. Am $\mathcal{F}$ Cardiol 1971;27: 481-90

3 Ho SY, Essher E, Anderson RH, Michaelsson $M$. Anatomy of congenital complete heart block and relation to maternal Anti Ro antibodies. Am $\mathcal{F}$ Cardiol 1986;58:291-4.

4 Frohn-Mulder IM, Meilof JF, Szatmari A, Stewart PA, Swaak TJ, Hess J. Clinical significance of maternal anti Ro/SSA antibodies in children with isolated heart block. $\mathcal{F ~} \mathrm{Am}$

\section{CORRECTION}

Impact of the 1991 NHS reforms on the availability and use of coronary revascularisation in the UK (1987-1995)

Black N, Langham S, Coshall C, Parker F. Heart 1996;76(suppl 4):1-31.

Data on the availability of whole-time equivalent (WTE) adult cardiac surgeons in Glasgow in 1994-95 was incorrect. There were 5.9 (not 10.9) WTE representing 3.38 (not 6.25) WTE per million population aged over 24 years (Appendix 1, page 25; fig 10, page 8). The comments on page 9 should read:

Consultant levels more than doubled in East Anglian, though the increase in South East Thames was only $27 \%$, in Greater Glasgow only $22 \%$ and there was no increase in North Western (fig 10).

Similarly, the fifth statement on page 22 under Objective 1 should read:
The availability of consultant surgeons showed little or no change between 1987 and 1995 in three regions but more than doubled in East Anglian.

NICK BLACK Professor of Health Services Research London School of Hygiene E Tropical Medicine, University of London London WC1E 7HT, UK

\section{NOTICES}

The First European Workshop on Hypertrophic Obstructive Cardiomyopathy under the auspices of the Working Groups on Myocardial Function and Cardiomyopathy of the European Society of Cardiology will take place on 31 October 1997 at the Imperial College School of Medicine, London, UK. Course fee (includes coffee, tea, lunch, and live teleconference) is $£ 125$. For further information please contact The Conference Centre (tel: 0171351 8172; fax: 0171376 3442; email a.c.allen@ac.ic.uk).

Practical Adult Cardiovascular Pathology Course will take place on 17 November 1997 at the National Heart and Lung Institute, London, UK. Course fee (includes coffee, tea, and lunch) is $£ 125 ; £ 100$ for juniors in training. For further information please contact National Heart and Lung Institute (tel: 0171351 8172; fax: 0171376 3442) 